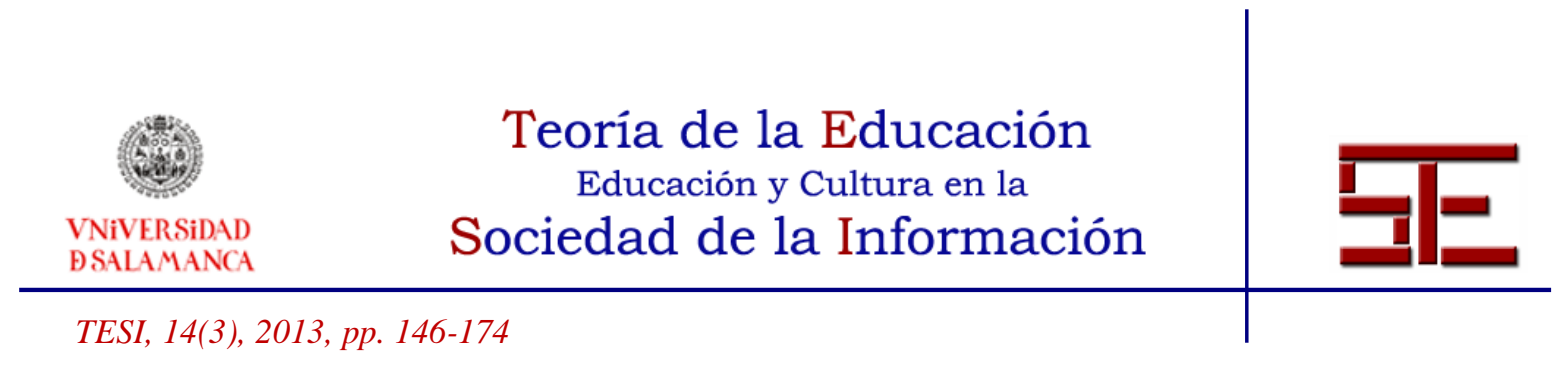

\title{
PRIMEROS LENGUAJES Y ÚLTIMAS TECNOLOGÍAS PARA LA EDUCACIÓN
}

Resumen: Este artículo es una reflexión acerca de cómo el aprendizaje de cada ser humano y el desarrollo cultural de la especie están vinculados a la posibilidad de traducir la realidad -lo que pensamos, lo que sentimos, nuestras interacciones- a sistemas de signos que, al tener significados compartidos, enriquecen nuestra comunicación intra e interpersonal. El lenguaje oral fue la primera tecnología pero al estar muy bien preparados genéticamente para él, lo aprendemos por inmersión; todos los demás, desde la escritura a los hipermedia, requieren ser bien enseñados y mejor aprendidos.

Concluimos destacando la necesidad de aprovechar las ventajas de todas las tecnologías hoy disponibles, para tratar de salvar la brecha digital sin olvidarnos de otras, como lectoescritora, que están en la base de las nuevas tecnologías; necesitamos para ello una teoría y una práctica de la educación que integre su complejidad y evite caer en reduccionismos simplistas.

Palabras clave: Aprendizaje de lenguajes, nuevas tecnologías, alfabetizaciones, hipermedia, internet, complejidad, teoría de la educación.

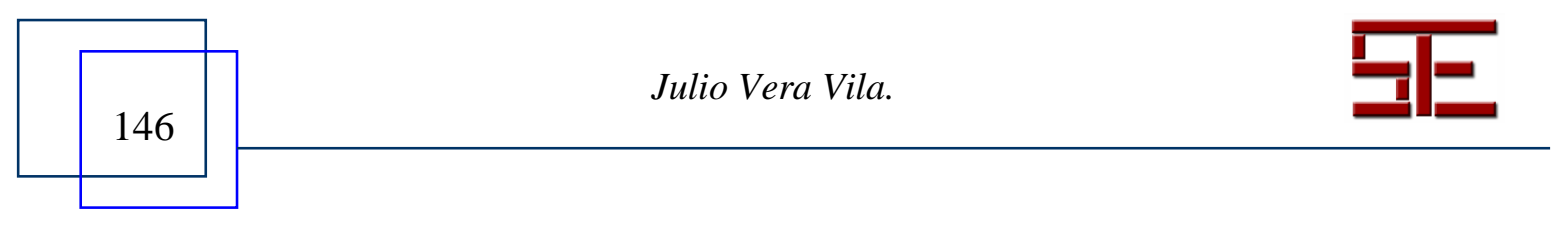




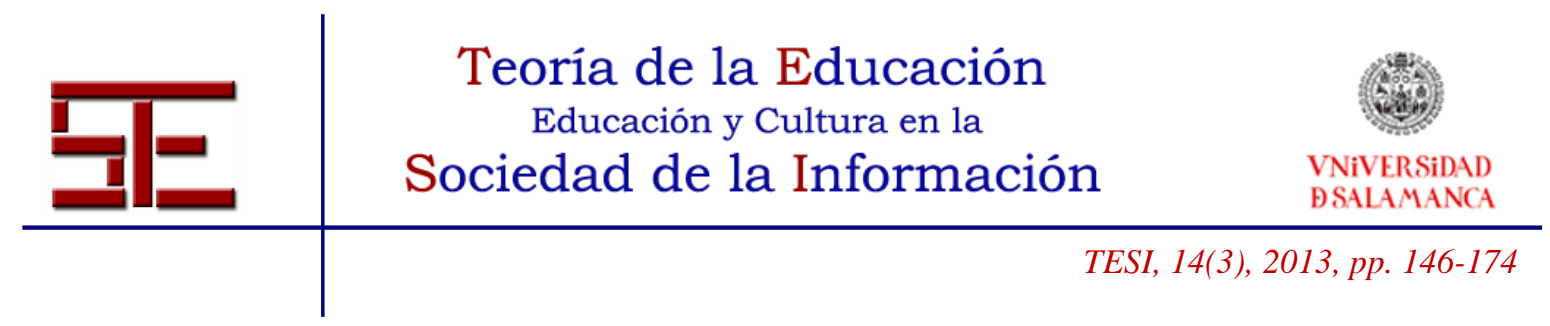

\section{FIRST LANGUAGES AND LAST TECHNOLOGIES FOR EDUCATION}

Abstract: This article is a reflection on how each human being's learning process and the cultural development of our species are connected to the possibility of translating reality -what we think, what we feel, our interaction- a system of signs that, having shared meanings, enrich our intrapersonal and interpersonal communication. Spoken language was the first technology but being well prepared genetically for it, we learn it through immersion; the rest of them, from written language to hypermedia, have to be well taught and even better learned.

We conclude by highlighting the necessity of taking advantage of the benefits provided by the new technologies available nowadays in order to overcome the digital divide, without forgetting others such as literacy acquisition, which are the base of new technologies. Therefore we need a theory and practice of education which comprises its complexity and avoids simplistic reductionism.

Key words: Language Learning, New Technologies, Literacy, Hypermedia, Internet, Complexity, Theory of Education.

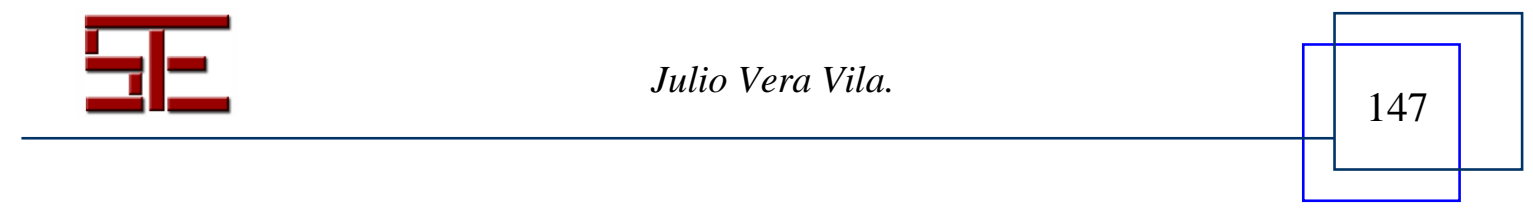




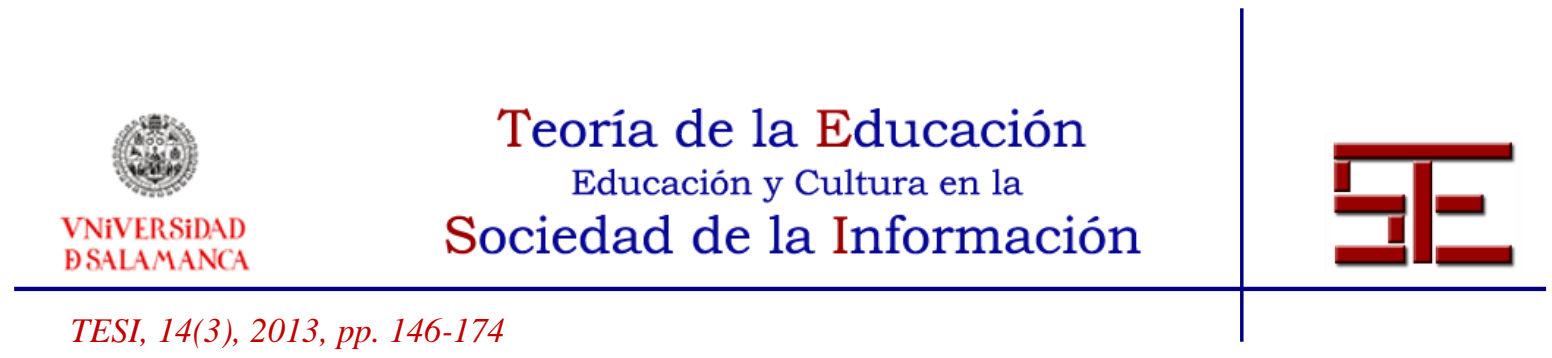

\title{
PRIMEROS LENGUAJES Y ÚLTIMAS TECNOLOGÍAS PARA LA EDUCACIÓN
}

Fecha de recepción: 26/06/2013; fecha de aceptación: 31/07/2013; fecha de publicación: 30/11/2013

\author{
Julio Vera Vila \\ juliovera@uma.es \\ Universidad de Málaga
}

\section{SISTEMAS SIMBÓLICOS, TECNOLOGÍAS DE LA COMUNICACIÓN Y DESARROLLO COGNITIVO}

\subsection{Los lenguajes como mediadores cognitivos del aprendizaje}

El desarrollo del ser humano, en concreto el de sus estructuras cognitivas está íntimamente ligado a la posibilidad de codificar la realidad a través de algún sistema de signos y a la de disponer de medios para comunicar el conocimiento. En este sentido, la historia filo y ontogenética de la mente humana está directamente relacionada y condicionada por la historia de la alfabetización y viceversa (Viñao, 1989, 375; y 1999, 94). Esta misma idea podría expresarse diciendo que cada nueva innovación cultural proporciona formas evolucionadas de aprendizaje (García Carrasco, J. y otros, 2012). Si analizamos los modos en los que el ser humano ha sido capaz de ir codificando la realidad desde la oralidad hasta nuestros días, nos damos cuenta de cómo el lenguaje (los sistemas de signos), el pensamiento y los procesos de comunicación han sido elementos de un mismo proceso de humanizador. Cualquier cambio en la tecnología de comunicación humana tiene efectos sobre el contenido de los mensajes que vehicula y sobre los modos y medios de pensar, reflexionar, expresarse, argumentar o de recordar; en definitiva sobre las propias estructuras y funciones cognitivas y, en consecuencia, en las cerebrales.

La primera diferencia la establece el lenguaje oral, la segunda el trasvase del habla a formas gráficas (grafías, dibujos, trazos, lenguaje icónico), la tercera la palabra escrita. La última, la digitalización de los contenidos y lenguajes en diferentes formatos. Aprender a hablar, leer y escribir una lengua no es un aprendizaje cualquiera, muy al contrario, se trata de un aprendizaje instrumental básico gracias al cual podemos manejar conceptos, expresar y compartir sentimientos, planificar nuestras vidas, gestionar el tiempo, acceder a una o más culturas y desarrollar nuestro cerebro. Los seres humanos somos plurilingües en el sentido de que tenemos la capacidad innata de aprender más de una lengua y de comunicarnos por múltiples sistemas de signos: los gestos, las señales de tráfico, el lenguaje matemático, las partituras musicales, los lenguajes computacionales, etc. Por ello, no hablamos de plurilingüismo pensando sólo en los idiomas, sino también en cualquier sistema de signos (textos, lenguaje gestual, el

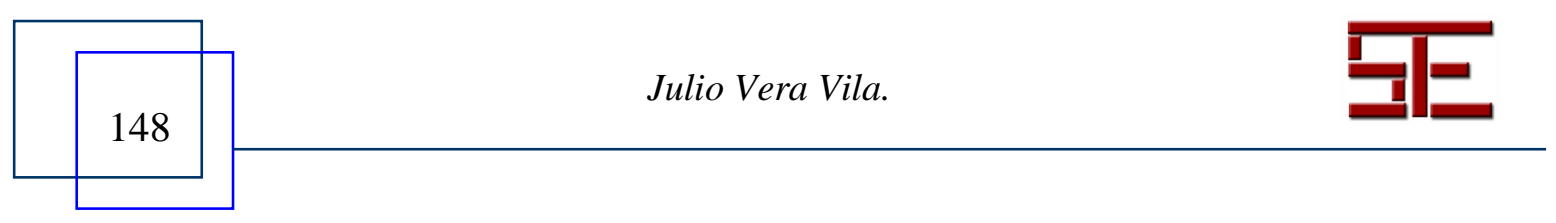




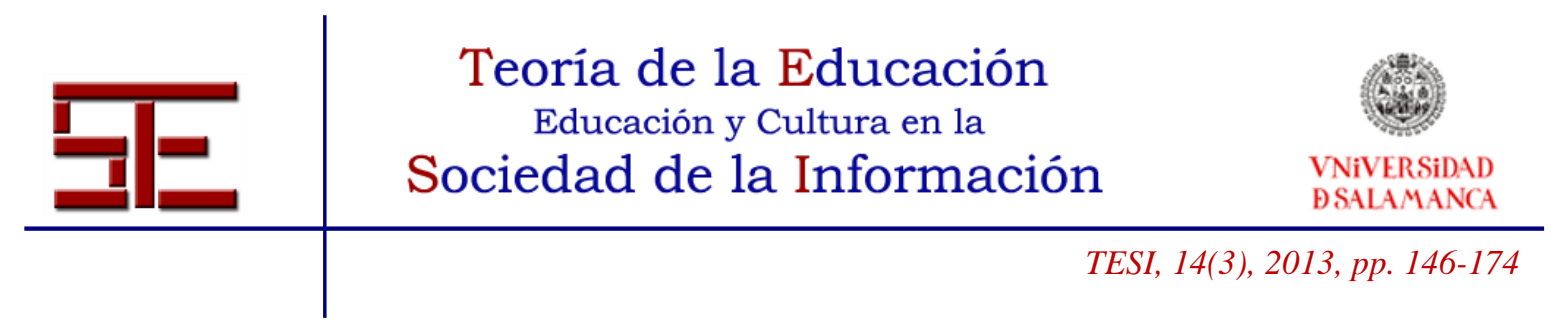

icónico, el matemático, el musical o el topográfico-espacial) que pueden ser utilizados con las recientes tecnologías para generar hipertextos plurilingües y multimedia, a la vez que desarrollan nuestras múltiples inteligencias (Gardner, 1993).

Los sistemas de codificación, los lenguajes, son soportes de las abstracciones que hace nuestro cerebro de la realidad en niveles cada vez más complejos. En ese sentido, podemos entender el desarrollo del pensamiento como un proceso de separación progresiva de más y más representaciones, de orden creciente de abstracción que se contienen vinculadas las unas a las otras formando un sistema (Gärdenfors, 2006, 30; García Carrasco, 2007, 498-499). El salto cualitativo trascendental para la educación no fue la aparición de las TIC (tecnologías de la información y la comunicación), sino la adquisición de sistemas de signos que nos permitieron nombrar cosas, acontecimientos, sentimientos, que no necesariamente estaban presentes ni en el tiempo ni en el espacio. Sin esta primera gran revolución comunicativa, la educación no habría sido lo que ha llegado a ser hasta la llegada de la era digital a finales de los años setenta del siglo pasado. Ha sido la invención de los diferentes lenguajes la que ha hecho posible que llegáramos a ser como somos, seres con consciencia, capaces de comprender la realidad, de enseñarla y aprenderla, y todo ello, fuera de un tiempo y lugar determinado. Desde este punto de vista, cualquier signo es virtual y tecnológico. Por ello, parece un error separar el libro y las nuevas tecnologías, la lectoescritura y lo digital, cuando el camino recorrido ha ido integrando de manera polivalente las aportaciones de cada tecnología. Bien es verdad que cada nueva integración no ha tenido sólo efectos sumativos, sino que ha supuesto un auténtico cambio cultural que ha afectado la manera como nos relacionamos entre nosotros, con la realidad, las formas de producción del saber e incluso el propio concepto de saber.

\subsection{Plasticidad cerebral, adquisición de lenguajes y desarrollo de las capacidades cognitivo-emocionales}

La plasticidad del cerebro constituye la base de casi todo cuanto somos y podemos llegar a ser. Cada vez que cambia la forma en que nos comunicamos cambia el cerebro y nuestro desarrollo intelectual. La aptitud del cerebro para aprender una nueva función intelectual es el resultado de su capacidad para establecer nuevas conexiones neuronales entre estructuras y circuitos ya preexistentes dedicados a otros procesos cerebrales más básicos. A los sistemas con esa capacidad tan versátil para reorganizarse y adaptarse a las nuevas demandas que reciben, se les denomina "sistemas abiertos" y posiblemente sea el cerebro uno de los mejores ejemplos de este tipo de sistemas (Wolf, 2008, 20-21).

Los avances de la neurociencia a lo largo del siglo XX y el actual, nos han hecho comprender mucho mejor cómo funciona el cerebro y cómo nuestras experiencias son capaces de cambiar las conexiones neuronales entre diferentes áreas del mismo, a la vez

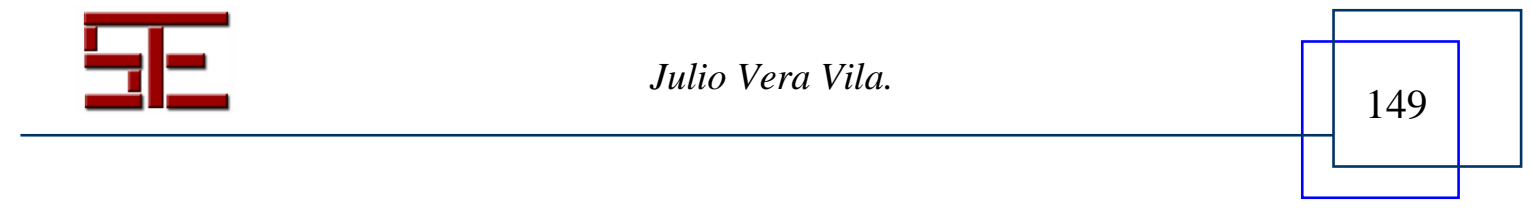




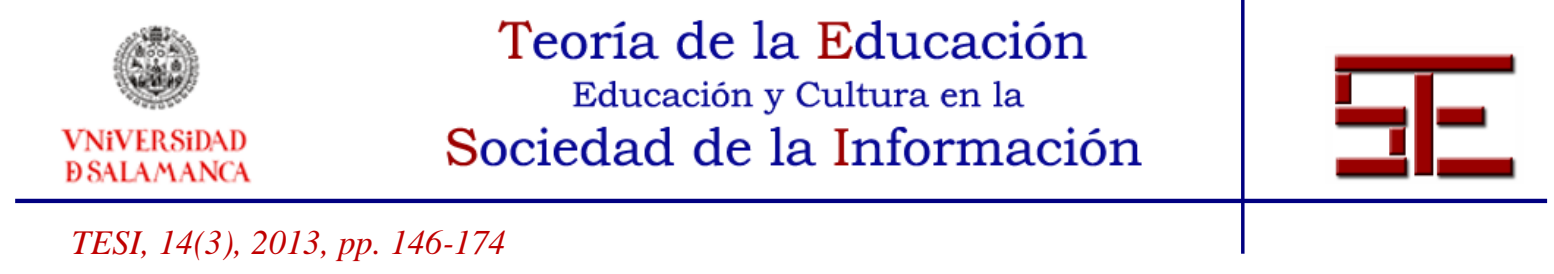

que aprendemos a hacer y pensar cosas nuevas. Antes se creía que el cerebro, una vez pasadas las etapas críticas, estaba ya clausurado: ni se creaban neuronas nuevas, ni eran posibles nuevas conexiones entre ellas. En la actualidad, gracias a los nuevos equipos de exploración del cerebro, sabemos que su plasticidad se da en todos los circuitos, ya se ocupen de ver, oír, leer, sentir, pensar o recordar y que todos ellos están sometidos a cambios. Esta plasticidad disminuye a medida que envejecemos, pero nunca desaparece, el cerebro tiene la capacidad de reprogramarse sobre la marcha, alterando la forma en que funciona. Aunque sus regiones se asocien con diferentes funciones mentales, las conexiones neuronales no son permanentes ni rígidas, cambian con la experiencia, las circunstancias y la necesidad. La plasticidad es la forma en que nos adaptamos a las condiciones cambiantes, la forma en que aprendemos nuevos datos y la forma en que desarrollamos nuevas habilidades, es el estado normal del sistema nervioso en el curso de la vida (Carr, 2011, 40-43).

A largo plazo, el contenido de un medio de comunicación importa menos que el propio medio a la hora de influir en nuestro pensamiento y en nuestros actos. Cada lenguaje y cada nuevo medio es un mediador entre nosotros y la manera en que vemos y operamos sobre la realidad, de manera que moldea lo que vemos y cómo lo vemos. Como indicaba McLuhan (2009), los efectos de la tecnología alteran los patrones de percepción continuamente y sin resistencia. Los medios no son sólo canales de comunicación como tampoco los lenguajes son sólo modos de representar la realidad, ambos proporcionan la materia sobre la que pensamos, pero también modelan el cerebro y el proceso de pensamiento. Hacer algo como hablar, escribir, leer, dibujar, ver una película, tocar un instrumento musical provoca cambios en el cerebro; y eso es así porque pensamos haciendo representaciones de la realidad con los lenguajes aprendidos. La posibilidad de mejora o deterioro intelectual es inherente a la plasticidad de nuestro cerebro. Los experimentos demuestran que, al igual que el cerebro puede crear nuevos circuitos neuronales y fortalecerlos con la práctica física o mental, también pueden disolverse si no se utilizan para aquello que se crearon; y esta plasticidad cerebral sirve para adquirir o perder tanto buenos como malos hábitos; también puede servir para adquirir patologías o adicciones (Doidge, 2008).

\subsection{Los lenguajes como formas de representar la realidad y operar mentalmente con ella}

Convendría siquiera brevemente distinguir entre lenguajes y medios de comunicación. Un lenguaje es un sistema de signos articulados para representar algo, así como el significado que le damos a ese algo; en cambio un medio es el soporte o el canal a través del que representamos la realidad con ayuda de los lenguajes. El libro es un medio, el texto escrito es un lenguaje; el violín es un medio, la notación musical es un lenguaje; un mapa es en esencia un lenguaje, un modo de representación, el papel o una

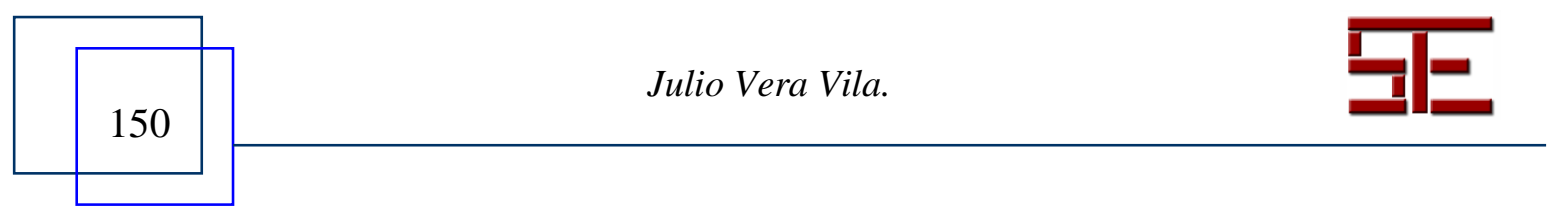




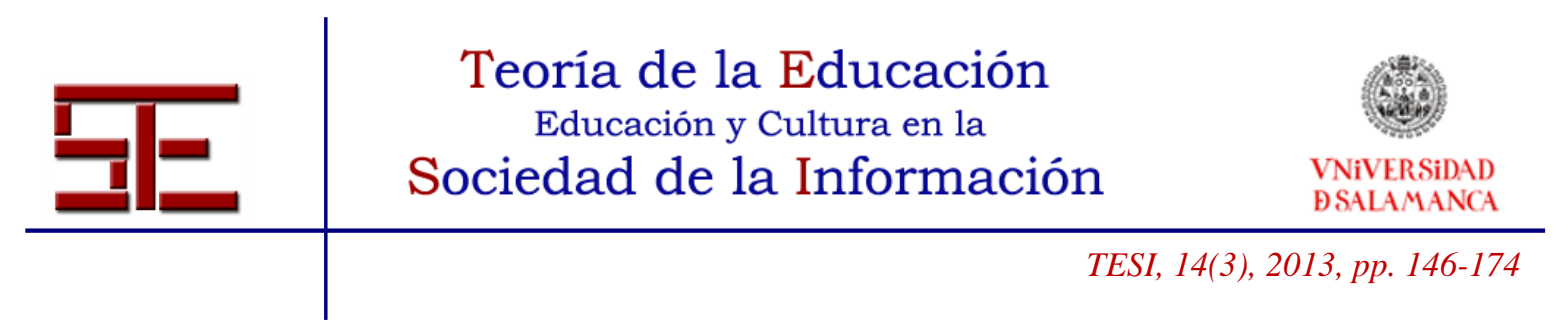

pizarra digital son los medios; internet es un medio capaz de utilizar muy diferentes lenguajes previamente digitalizados en diferentes formatos.

Pues bien, los actos comunicativos son la esencia de los procesos educativos porque promueven cambios hacia el interior y exterior de los sujetos y de las personas entre sí. Por eso los lenguajes, los medios, los mediadores, son la innovación primordial, son acumuladores de experiencia que transportan los significados culturales a través del tiempo y del espacio, ya sea de manera presencial o virtual. Gracias a las huellas que dejaron con las tecnologías disponibles, estamos conociendo y comprendiendo ahora, culturas del pasado. Con las tecnologías actuales ese conocimiento puede ser digitalizado en forma de sonido, imagen y texto y estar a disposición de cualquier persona alfabetizada e interesada por el devenir de la especie. Si ha llegado hasta nosotros es porque hubo un medio de representación (lenguaje), un soporte o medio (por ejemplo, el papiro) y un cerebro alfabetizado para descifrarlo y comunicarlo en forma accesible (el investigador). García Carrasco y García del Dujo (2001, 387-412) hacen un excelente análisis de la evolución seguida por los sistemas de comunicación: oral, lectoescritora y digital, así como de las diferentes formas culturales a que dieron lugar. Ese análisis me parece imprescindible para comprender la verdadera dimensión de la alfabetización digital y la de sus niveles previos, sin la cual aquella sólo puede ser superficial, aparente o ilusoria.

El proceso intelectual de transformar la experiencia en algo abstracto capaz de representarla supuso una revolución tecnológica de enorme valor. Los cimientos de todo el desarrollo tecnológico que estamos viviendo en la era digital se fraguaron de manera sólida cuando se inventó la lectoescritura basada en el alfabeto. Si queremos tener un conocimiento profundo del significado educativo de las nuevas tecnologías de la información, debemos comprender la fascinante revolución que supuso la invención de la lectoescritura. Ella junto a otros lenguajes como las matemáticas o la música están en la base de lo que vemos y somos capaces de hacer digitalmente con los ordenadores a través de internet, sean del tamaño de un smartphone o del de una pizarra digital.

Como muy acertadamente nos indica Edgar Morin $(2001,48)$ la prehistoria pasa a ser cada vez más la ciencia fundamental de la hominización porque representa como ninguna otra la emergencia de la humanidad desde la animalidad, el proceso a través del cual podemos comprender el surgimiento de las formas de representación abstracta, los lenguajes, la bipedización, el erguimiento del cuerpo, la racionalidad, el desarrollo cerebral en tamaño, forma y funcionamiento; el proceso de formalización de la educación; los procedimientos de alfabetización, al mismo tiempo que se construye la cultura, los saberes, las teorías, las explicaciones del mundo.

Nuestra evolución ha estado ligada a los lenguajes y a las tecnologías como mediadores entre los seres humanos y la realidad desde hace millones de años y cada nuevo invento se ha ido sumando a los anteriores transformándose en algo más potente y diferente, con

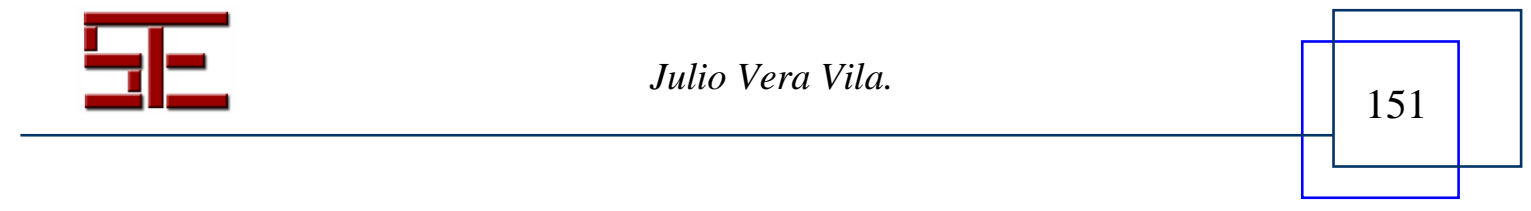




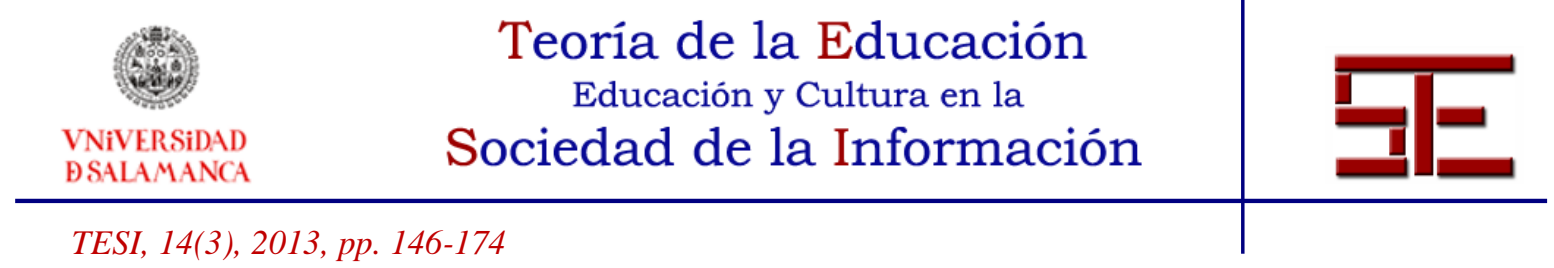

efectos también diferentes. Por eso, debajo de las rutilantes y efímeras innovaciones tecnológicas que nos ofrecen las industrias de las telecomunicaciones, de la computación o de los medios de comunicación, subyacen lenguajes y medios que las soportan y de cuya alfabetización depende la profundidad y alcance del uso que podamos darles. De hecho, algunas de las ventajas que se predican de las tecnologías digitales ya existían anteriormente de manera menos sofisticada, sólo que no hablamos de ellas con el mismo entusiasmo, por ejemplo la conectividad, la interacción, la interactividad, las redes sociales, la inteligencia colectiva. Y es que no puede ser de otra forma porque la tecnología digital es la digitalización de lo previamente existente, si bien es verdad que la digitalización es mucho más que la suma de lo anterior, es un medio nuevo, un contexto diferente y una nueva cultura. La brecha digital no es la única posible, lamentablemente hay tantas brechas posibles como carencias en la adquisición de los lenguajes que nos permiten pensar y comunicarnos con los demás. Las brechas más peligrosas son aquellas que no se ven, aquellas de las que no se tiene conciencia, las que carecen de interés comercial o se dan por superadas.

\section{INTERNET, REDES E HIPERTEXTOS: EL JARDÍN DE LOS SENDEROS QUE SE BIFURCAN}

\subsection{Las nuevas tecnologías para el aprendizaje y el conocimiento}

Jorge Luis Borges, fue uno de los mejores escritores en lengua castellana. Uno de sus relatos más importantes es el titulado "El jardín de los senderos que se bifurcan”, donde un astrólogo se propone construir un laberinto infinitamente complejo y sin fin. Esta puede ser la metáfora literaria de los hipertextos de internet. La novela de Julio Cortázar, "Rayuela", podría ejemplificar cómo dentro del laberinto de la información en el que nos movemos actualmente, cada lector puede hacer su propio recorrido, guiado nada más que por sus intereses, conocimientos y destrezas. Uno no va donde quiere, sino donde puede.

Internet es un conjunto de redes de comunicación interconectadas que forman una única red lógica de alcance mundial. Su funcionamiento es muy similar al de las redes neuronales de nuestro cerebro, con la diferencia de que sabemos con certeza que el cerebro (el aprendizaje de alto nivel) fue antes que internet, que internet es su producto, y que desde entonces está a su servicio y al de las demandas de cualquier usuario, sean cuales sean sus intereses o su grado de formación. También su funcionamiento es parecido al razonamiento lógico en tanto en cuanto los razonamientos se construyen en base a cadenas de conceptos que representan cosas de una misma clase y, también en el sentido de que con los mismos conceptos pueden construirse argumentaciones diferentes e igualmente lógicas aunque unas tengan más verosimilitud y/o objetividad que otras.

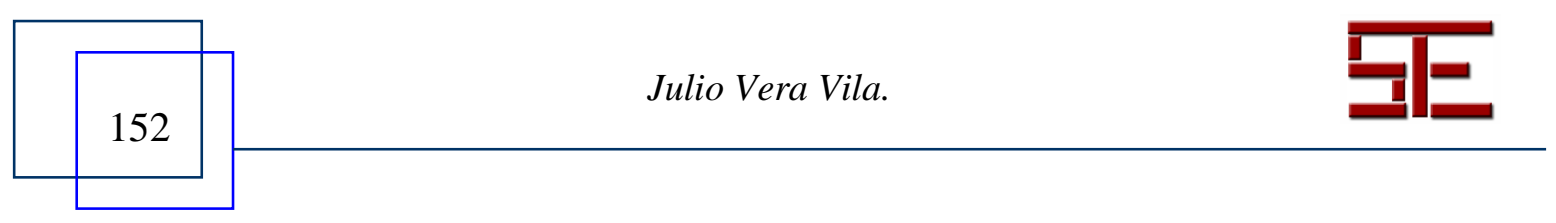




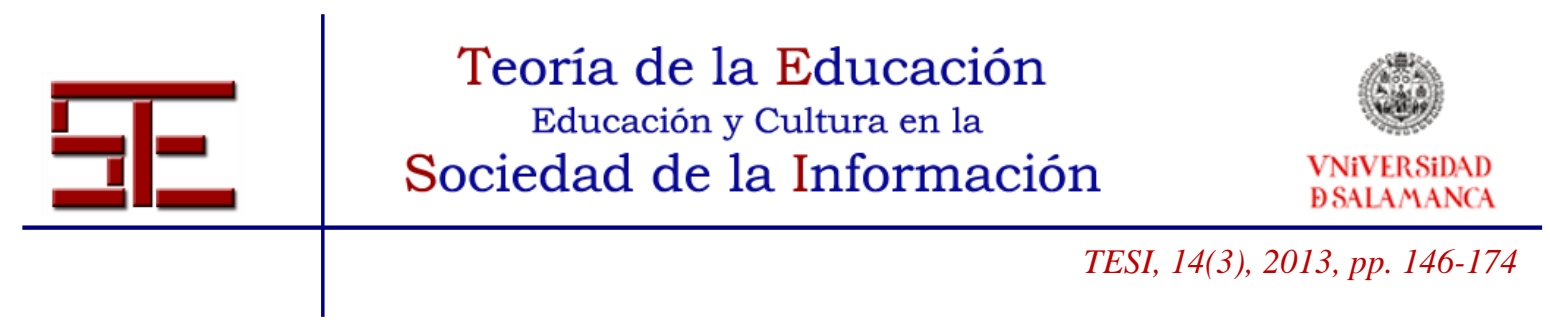

¿Qué aportan las tecnologías de la era digital a la enseñanza y al aprendizaje? Aportan mucho, sin duda. Los sistemas de signos y los medios de comunicación se complementan unos a otros, al igual que las personas y sus inteligencias entre sí. Las nuevas tecnologías permiten crear redes de sistemas de representación multi-lenguajes, mientras que las personas son capaces de crear inteligencias interconectadas (Kerckhove, 1999a y 1999b; Lèvy, 2004). Las tecnologías actuales están basadas en el uso simultáneo de múltiples lenguajes que dan lugar a hipertextos e hipermedias, entendiendo por tales aquellos instrumentos para crear, manipular y presentar unidades de información (nodos) capaces de relacionarse en redes de significado según diferentes criterios (Rodríguez Diéguez, J.L., 1995; Kerckhove, 1999a). Pero el nodo más importante de la red y el que debe ser más competente si quiere ser creativo y no mero consumidor es el usuario. Esto es crucial tenerlo en cuenta para cualquier uso educativo de las nuevas tecnologías, basadas -no lo olvidemos- en los viejos lenguajes. El hecho de que los avances tecnológicos hayan logrado crear unas interfaces muy intuitivas que funcionan a golpe de clip o desplazando el dedo sobre la pantalla crea una ilusión de falso conocimiento, tan iluso como creer que por abrir un libro y pasar la vista por sus páginas, lo hemos leído, comprendido y relacionado con todo el conocimiento existente.

La ventaja del hipertexto es que puede ser hipermedia, no lineal, plurilingüe, reunir información muy dispersa, actualizarse y adecuarse al nivel de desarrollo del usuario, ya sea individual o grupal. El usuario puede modificar el documento, compartirlo, enlazarlo con otros contenidos y someterlo a procesos muy diferentes. La información siempre está disponible en cualquier momento y en cualquier lugar con conexión a Internet. Pedagógicamente la calidad vendrá determinada por la calidad de los aprendizajes que potencie, por la calidad de su diseño y por la calidad de los proyectos pedagógicos en los que se inserte (Vera, 1997).

Por su parte, el interés educativo de internet es enorme por varias razones: a) en cierto sentido es un duplicado de la vida real; b) permite la consulta remota de archivos de hipertexto, el envío y recepción de correo instantáneo, la transmisión de archivos en formatos múltiples y multimedia; tener conversaciones en línea entre muchas personas, formar redes a la medida con ellas; la comunicación multimedia, el acceso remoto a programas electrónicos, la descarga y subida de archivos, etc.; c) permite utilizar lo que otros han hecho, pero también recrearlo o añadir nuevas creaciones, ya sea individualmente o en grupo; d) todo ello puede hacerse desde cualquier lugar donde exista conexión, con o sin cables, desde aparatos tan diversos como un portátil, una teléfono inteligente o una tableta, entre otros. Suele decirse que Internet es muy motivador. Sin duda lo es. Pero al ser sus posibilidades tan amplias como el nivel de las competencias y objetivos del usuario, también exige mucho esfuerzo cuando el usuario es exigente. Merece la pena, por lo tanto, hablar también de sus limitaciones: a) en general, no tiene inteligencia moral, ni emocional: le sirve tanto al asesino como al policía o al juez; b) no mueve nuestras neuronas, no nos afecta emocionalmente, ni

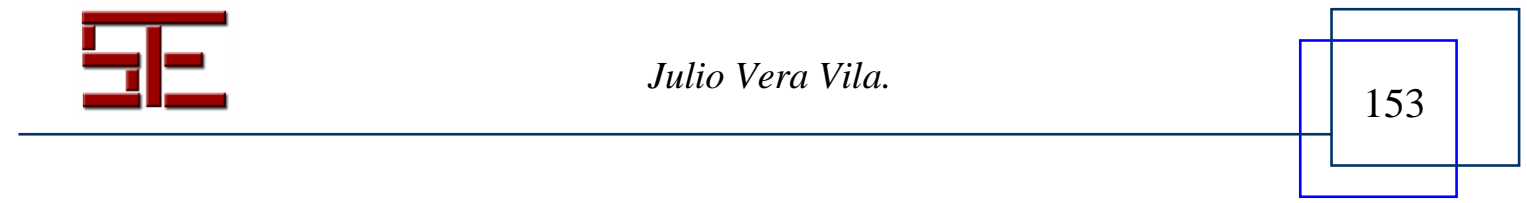




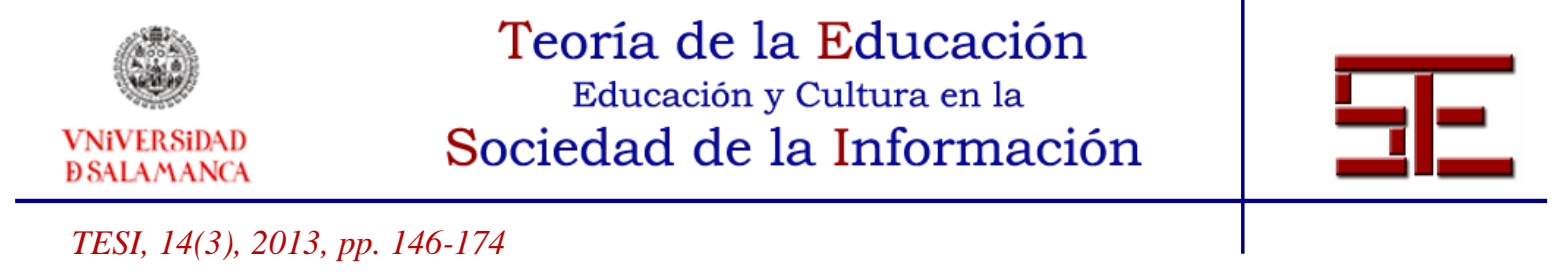

moviliza nuestra voluntad si no tomamos la iniciativa nosotros o el autor de los contenidos a los que accedemos; c) necesitamos algún criterio para jerarquizar lo que hay en la red según su valor educativo, su veracidad, rigor, el tratamiento que le queramos dar, etc.; c) sólo es capaz de hacer lo que nosotros seamos capaces de hacer.

Ni la red, ni el profesor pueden aprender por el alumno. Lo que potencia internet es el aprendizaje autónomo del alumno, tanto si lo hace individualmente como en grupo, siempre que tenga profesores preparados para guiar su aprendizaje. En los entornos digitales, el protagonista principal no es la ingeniería informática, sino la mentalidad pedagógica del equipo de profesores y los procesos de aprendizaje de los alumnos.

Cada nueva tecnología es un desafío y una oportunidad para la educación, y todas ellas deben tener un papel importante para lograr un replanteamiento metodológico, didáctico, curricular, organizativo en todos los ámbitos educativos, si queremos mejorar la calidad de los procesos y contextos de aprendizaje. Pero no debemos olvidar que los verdaderos hipermedia están en el cerebro de las personas con alto nivel de alfabetización, un nivel que hoy es más exigente que antes porque combina, a través de la red más lenguajes y medios que nunca (Castells, 2001, 229). Para que haya auténticos hipermedia con valor educativo, debe haber una preocupación real por el destino cultural de los usuarios, de lo contrario no pasaremos del hábito consumista, de la necesidad de sentirnos integrados en el grupo a través de los chats y de las redes digitales, de la multitarea superficial y breve, de la hiperestimulación sensorial.

\subsection{Nativos e inmigrantes tecnológicos. Los usuarios que enseñan y aprenden}

Actualmente se habla de los nativos digitales (Prensky, 2001a) para referirse a las generaciones de jóvenes que han nacido en culturas que además de otras herramientas comunicativas y sistemas de signos, tenían disponible el acceso y uso de la tecnología digital. Se supone que los nativos digitales, simplemente por el hecho de haber nacido rodeados de ordenadores, videojuegos, pantallas, internet, móviles y tabletas, dominan las nuevas herramientas tecnológicas, son capaces de acceder a la información disponible, interactuar entre ellos, manipular los contenidos y generar nuevas formas de producción y tratamiento del saber y el conocimiento. Es cierto que los estudiantes de hoy día, al haber nacido en entornos digitales, han adquirido hábitos de pensamiento y de procesamiento de la información diferentes: están acostumbrados a recibir información muy rápidamente, les gusta hacer varias tareas a la vez, prefieren primero lo gráfico y luego lo textual y no al revés; prefieren el acceso aleatorio como en el hipertexto que no el lineal, están acostumbrados a la instantaneidad, funcionan mejor conectados y en red, etc. También es cierto que algunos profesores inmigrantes digitales tienen muy poco aprecio por estas nuevas habilidades y se cierran a considerar las posibilidades pedagógicas de las tecnologías de la era digital y de internet.

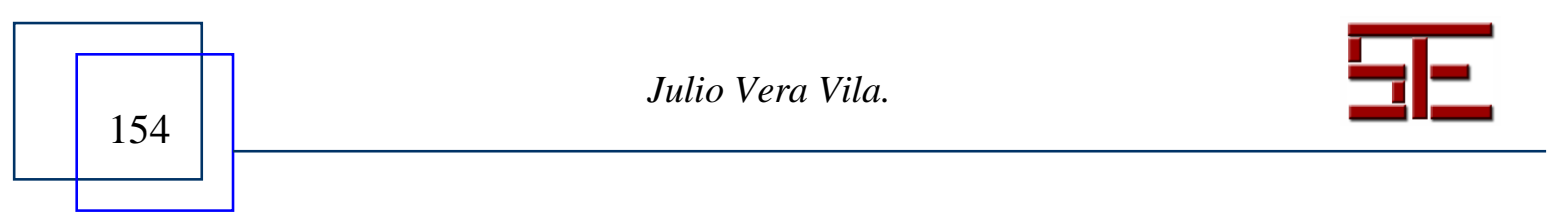




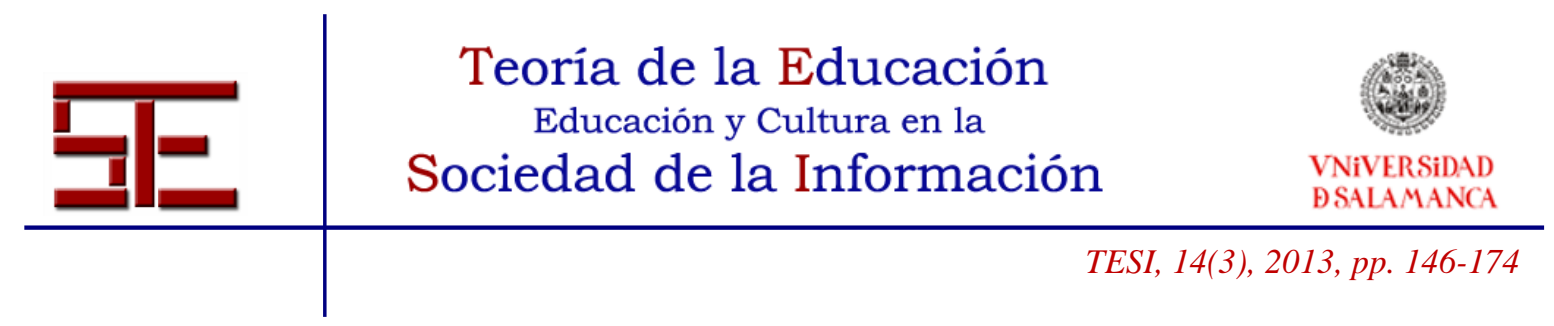

Sin embargo, lo que ponemos en duda es que las habilidades de los denominados nativos digitales deban ser tomadas como las mejores para el aprendizaje, y mucho menos las únicas (Carr, 2011). El haber nacido en una época o en otra no parece lo más relevante cuando una de las metas de la educación de hoy debería consistir en prepararnos para ser buenos migrantes culturales, capaces de usar indistintamente unos sistemas de símbolos u otros, unos procesos de aprendizaje u otros; unas tecnologías $\mathrm{u}$ otras. Así lo que proponemos tanto para los nativos de la era Gutemberg, como para los nativos digitales, es una educación que les permita migrar de unas tecnologías a otras, con una visión del mundo intercultural, abierta y humanista. Algunos de nosotros nacimos entre libros, libros de texto, revistas o prensa escrita y no por ello desarrollamos las competencias lectoescritoras por simple inmersión. Seguramente porque el software para hacer funcionar estos productos culturales lo adquiere nuestro cerebro a través de la alfabetización, es decir, requiere haber aprendido a disfrutar de sus contenidos, tener una cierta autodisciplina, vencer dificultades y darle un sentido a nuestras vidas. Los contenidos no suben a la mente, más bien es al revés, es la mente la que ha de trabajarlos para asimilarlos y convertirlos en conocimientos integrados en una estructura con significado. Esto, no parece haber cambiado con respecto a las tecnologías más recientes. Entre los nativos digitales, como entre los inmigrantes digitales, los hay de muy diferentes tipos, unos más alfabetizados que otros, unos más creativos y otros más consumidores pasivos. Lo que no nos cabe ninguna duda es que las tecnologías, sean las que sean, una vez mediadas pedagógicamente son potentes herramientas para el aprendizaje, el conocimiento y la comunicación. Esa mediación es precisamente la que puede hacer que unas tecnologías de la información y de la comunicación (TICs) se transformen en tecnologías del aprendizaje y el conocimiento (TACs). Nuestra responsabilidad como docentes es aprovecharlas para propiciar entornos innovadores y procesos de aprendizaje polivalentes que permitan que los alumnos adquieran las competencias del siglo XXI, entre ellas la del dominio de idiomas y una mentalidad intercultural.

Nacer en un contexto cultural como el actual, no garantiza que la educación informal, la espontánea, sea suficiente para un uso competente de ninguna de las tecnologías disponibles, tampoco las digitales (Plowman y McPake, 2013). Los inmigrantes digitales son aquellas personas que han tenido que migrar desde los antiguos lenguajes y medios de comunicación a las nuevas tecnologías digitales, pero algunos de esos inmigrantes también han sido los que, sobre el dominio de lo anterior, han alumbrado lo nuevo. Los impulsores de los lenguajes computacionales, de internet, de los ordenadores y de los videojuegos no eran, la mayoría de ellos, nativos tecnológicos; eran sencillamente muy competentes en lo que ya existía y tenían una inquietud personal que orientaba sus vidas de una manera creativa. Muy diferente es la actitud meramente consumista de productos ya elaborados por otros. Por otra parte, los nativos digitales, son también nativos lectoescritores y nativos en otros muchos sistemas de

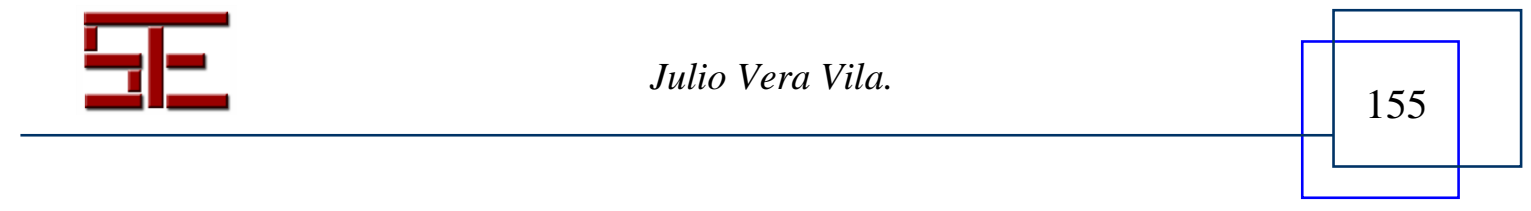




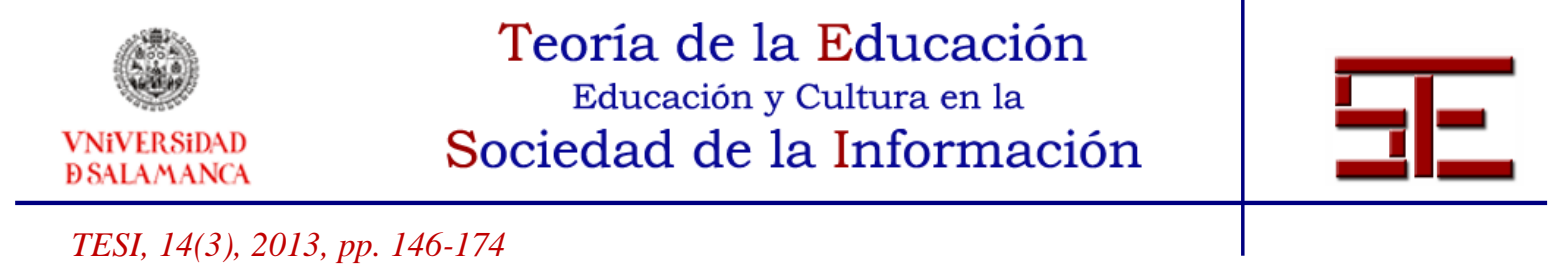

signos ya mencionados y, a la vista está, que la educación informal es completamente insuficiente para una alfabetización lectoescritora, cuánto más en sistemas plurilingües; y es que una cosa es convivir con la realidad virtual y otra muy diferente hacerlo de manera competente, autónoma y cívica.

Los nativos y los inmigrantes digitales tienen mucho que aprender unos de otros. Los profesores tienen la obligación deontológica de aprender a vivir en este mundo, el actual, y los nativos digitales tienen la responsabilidad de comprender que educarse es recibir un legado que debe ser asimilado y recreado al servicio del bienestar general. Lo que los profesores han de hacer es aprovechar los hábitos cognitivos y experienciales que los alumnos ya traen de la cultura digital consumista para enseñar de otra manera lo más valioso de la cultura humana, plural, rica, diversa y humanizadora. Para ello es urgente comenzar a formarse y a usar todo el potencial que ofrecen todas tecnologías.

\section{LAS BRECHAS DE LOS ANALFABETISMOS}

\subsection{Aprendizajes y carencias asociadas a la oralidad y a la lectoescritura}

Las tecnologías no son sólo herramientas que nos ayudan a hacer cosas, sino que cuando las usamos nos cambian, afectan nuestro cerebro, la manera de hacer, de pensar, de sentir y el significado que le damos a todo ello. Como decía McLuhan (2009), el medio es el contenido, pero sobre todo es el mensaje. Una herramienta hace lo que nosotros queremos, pero nosotros también acabamos siendo aquello que su uso configura. Las tecnologías no son meras ayudas exteriores, sino también transformaciones interiores de la conciencia, y especialmente cuando afectan a la palabra, porque las palabras son el hilo que teje nuestras mentes (Ong, 1993), aunque habría que añadir que no el único.

El lenguaje oral fue posible gracias a la evolución de nuestros órganos de fonación y de nuestros cerebros de tal manera que los niños actuales nacen ya con estructuras neuronales que les permiten aprender muy temprano algo tan difícil como un idioma, sea el que sea; esas pre programaciones sólo determinan la estructura básica pero no el idioma a aprender porque eso sí es altamente cultural y aprendido (Martínez y Arsuaga, 2002, 332; Arsuaga, 2002, 331-334). Como el lenguaje oral se aprende muy pronto y tenemos tan arraigada culturalmente la lectoescritura, parecería que también es innata, pero sabemos que no es así, la lectura y la escritura son una invención humana, un añadido cultural que sólo se adquiere mediante aprendizaje intencionado y cuanto más elaborado mejor. El incumplimiento del derecho del menor a ser enseñado como nativo lectoescritor es de los que más daño puede causarle en su devenir vital. Nuestras mentes tienen que aprender a traducir los caracteres simbólicos que vemos al lenguaje que entendemos y no pueden hacerlo solas sin generar auténticas lagunas y retrasos. "No nacimos para leer. Los seres humanos inventamos la lectura hace apenas unos milenios.

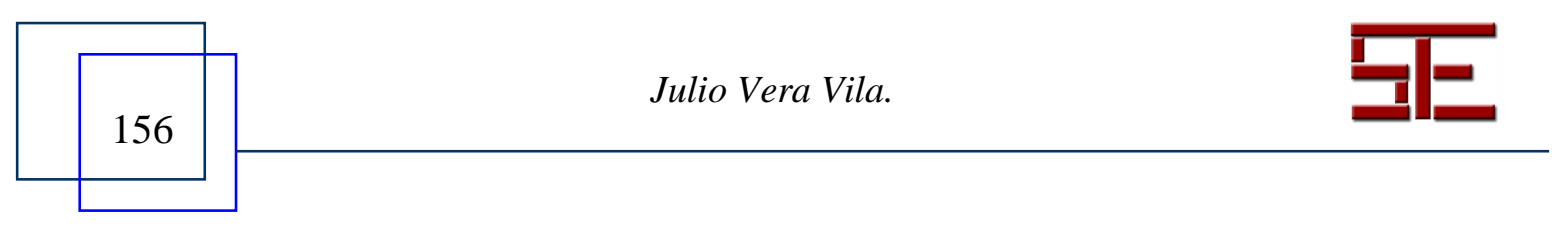




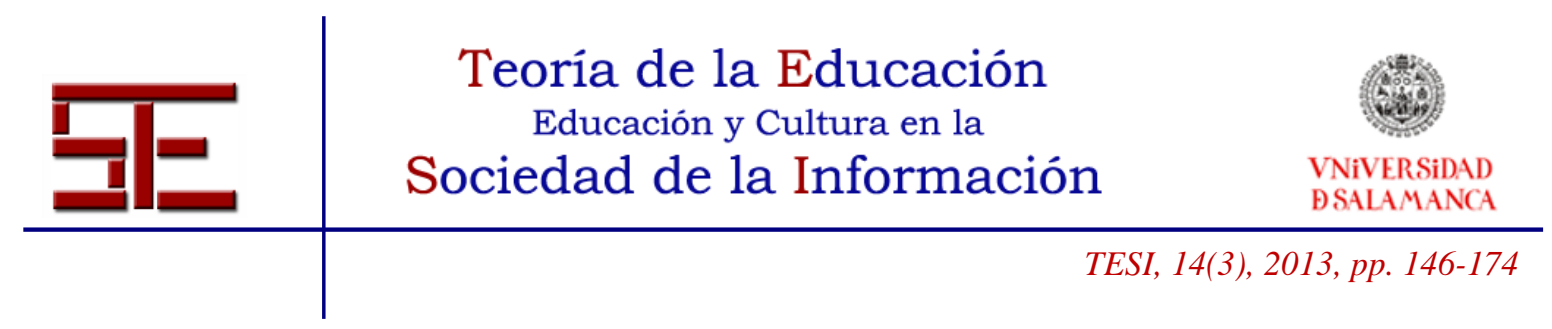

Y con ese invento modificamos la propia organización de nuestro cerebro, lo que a su vez amplió nuestra capacidad de pensar, que por su parte alteró la evolución intelectual de nuestra especie" (Wolf, 2008, 19).

En una cultura puramente oral el conocimiento es lo que retenemos en la memoria y por lo tanto está limitado a lo que somos capaces de recordar. Las palabras nos ayudan a conservar el conocimiento y a comunicárselo a otros; en este contexto, la dicción, la sintaxis, el ritmo, la entonación, la gestualidad, son muy importantes y por lo tanto se desarrollan cada vez que nos expresamos verbalmente.

De manera parecida, aprender a leer en un idioma determinado nos condiciona y nos transforma en dos dimensiones complementarias pero diferentes. Una de ellas viene determinada por la forma en que los caracteres propios de ese idioma hacen que las conexiones neuronales del cerebro lector de un chino sean muy diferentes de las de un lector castellano. La otra hace que el contenido, el tema acerca del que leemos, vaya conformando nuestra manera de pensar y aquello sobre lo que pensamos (Wolf, 2008, 21). Por lo tanto, en la experiencia lectora se concitan varias dimensiones del ser humano: lo biográfico, lo intelectual y lo biológico. Por un lado el cerebro, al leer, da lugar a una competencia nueva que le dota de un repertorio simbólico y semántico que antes no tenía. Por otro lado, al leer ampliamos nuestra capacidad de pensar y sentir, activamos procesos cognitivos y emocionales: visuales, auditivos, representacionales, de atención, memorísticos, asociativos, analíticos, sintéticos, de identificación o disonancia emocional y lingüísticos (morfológicos, sintácticos, semánticos, etc.).

Cuando observamos a alguien leyendo, en la capa más superficial y externa lo que vemos es el acto de leer, pero por debajo, en los niveles no observables, se están sucediendo procesos de atención, percepción conceptual, lingüísticos, motores, emocionales, etc. Estos procesos se basan, a su vez, en estructuras biológicas formadas por grupos de neuronas dirigidas por la interacción entre los genes y el entorno.

Sólo después de que el cerebro lector ha integrado toda la información visual, auditiva, semántica, sintáctica y deductiva, comienza a abrirse la posibilidad de relacionar aquello con los pensamientos, las emociones y las interpretaciones personales. Es en ese momento cuando lector/a y escritor/a confluyen como dos inteligencias interconectadas, aumentando exponencialmente las posibles combinaciones de sentido entre lo escrito y lo leído.

Desde el punto de vista educativo hay en el aprendizaje de la lectoescritura una cuestión trascendental: al parecer no existen genes específicos para la lectura y eso significa que nuestro cerebro tiene que conectar las estructuras de la visión (imagen representativa) y el lenguaje (sonido representativo) para adquirir la nueva habilidad lectora. La lectura es un accesorio cultural que requiere ser fijado desde el principio de manera inteligente a través de estímulos educativos del contexto sostenidos en el tiempo hasta quedar

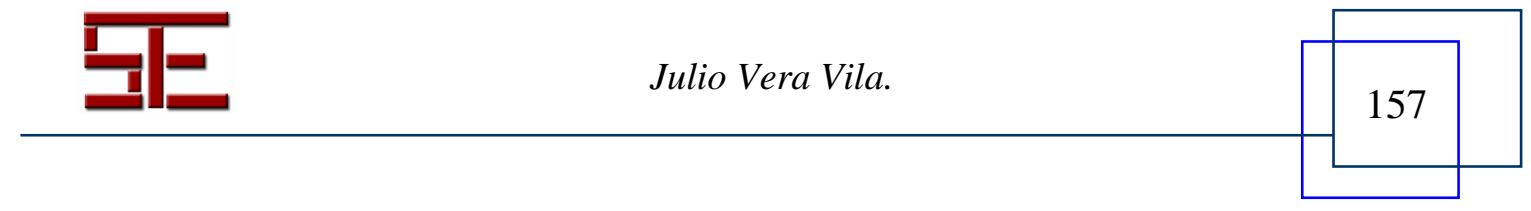




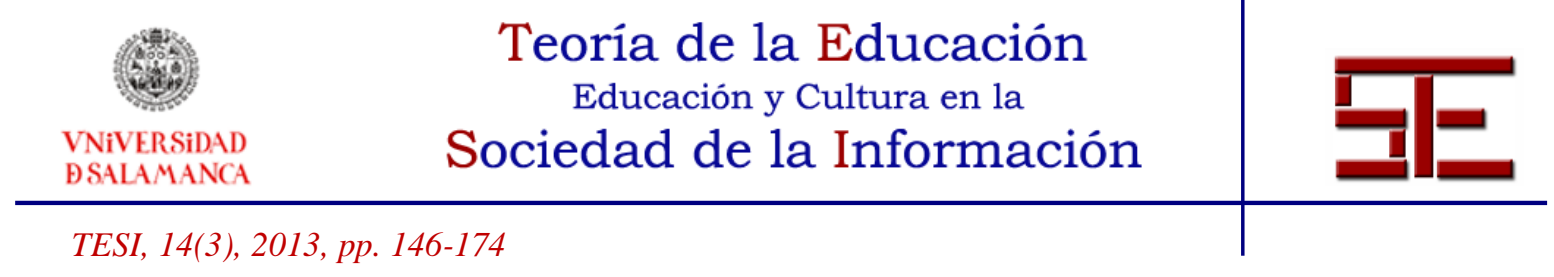

fijados en el cerebro. Esta circunstancia explica la brecha lectoescritora, el abismo cultural, que se abre entre quienes nacen y se desarrollan en entornos enriquecidos en todos los componentes implicados en la nueva competencia (sonidos bien articulados, narraciones, escuchar hablar correctamente, capacidad para imaginar historias, o que alguien les cuente un cuento) y los que lo hacen en entornos muy deficitarios en esos dominios. La frecuencia con la que el niño reciba los estímulos necesarios en sus primeros cinco años de vida será determinante para sus aprendizajes posteriores, entre ellos, los más determinantes de todos, los demás sistemas simbólicos de representación.

El cerebro del niño pequeño se prepara para la lectura mucho antes de entrar en contacto con textos escritos y utiliza como materia prima para ello cada estímulo que es capaz de percibir, ya sea una imagen, un sonido, una palabra o un concepto. Desde este punto de vista hay dos infancias muy diferentes: en una ocurre casi todo lo que esperamos; en la otra se cuentan pocos cuentos; se aprende poco vocabulario y el niño se queda cada vez más rezagado, antes incluso de empezar a leer. Gracias a esta suerte de entorno enriquecido, eso que en digital denominamos asombrados realidad aumentada (kerckhove, 1999a), el cerebro del niño ha sido capaz de relacionar e integrar la información procedente de varios sistemas: visión, cognición y lenguaje; y cualquiera de ellos que se estimule, activa a los otros: el sonido despierta su atención, la atención percibe formas, su cerebro asocia y su sistema emocional va conectando sus experiencias a lo placentero, al cuidado, a la atención, al afecto.

Pensemos en la situación contraria, la de los niños con los que no se interacciona a través de todo este amplio conjunto de actividades tan diversas que preparan para la lectura. Estos niños que crecen en un entorno con pocas o ninguna experiencia de alfabetización lectoescritora parten ya con una desventaja cuando acceden a la escuela infantil que probablemente se irá incrementando en etapas posteriores si no se actúa con diligencia. Según algunas investigaciones, a los cinco años de edad, algunos niños procedentes de entornos lingüísticos empobrecidos han oído 32 millones de palabras menos dirigidas a ellos que un niño procedente de entornos medios. Estos niños, a los 11 años tienen un retraso de tres cursos con respecto a la media de sus compañeros (Wolf, 2008, 126); muchos de ellos crecieron sin libros en sus casas por lo que podríamos decir que lamentablemente tuvieron que hacerse inmigrantes lectores en la escuela, mucho después que otros compañeros. Cronológicamente eran nativos lectoescritores, su especie llevaba miles de años con esa habilidad adquirida, pero en su entorno no estaban presentes los utensilios e interacciones suficientes para hacérsela accesible a ellos. Aunque tuvieran a su alcance ordenadores y samartphones no podrían leer con fluidez en ellos. No es de extrañar que algunas investigaciones nos estén alertando de algunos mitos acerca de las supuestas competencias que se les atribuyen, sin más, a los denominados nativos digitales (Plowman y McPake, 2013).

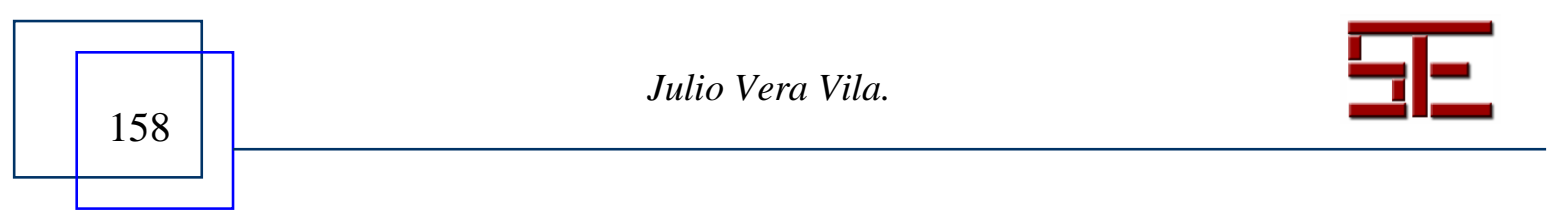




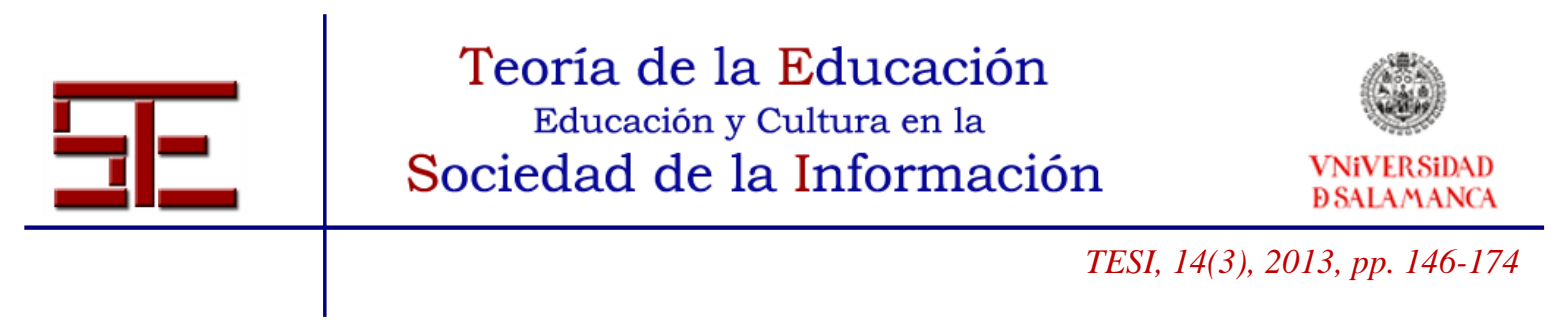

Muy probablemente esto que decimos sobre la lectura y su sistema de representación simbólica podría decirse de otros sistemas de signos como los musicales, matemáticos, topográficos o pictóricos, de los que dependen otros tipos de inteligencias asociados a lenguajes o convencionalismos como en el caso de la inteligencia intra e interpersonal (Gardner, 1993; Vera, 2010). ¿Cuánto influyó en Mozart o Picasso el haber sido alfabetizados de manera temprana en los lenguajes de la música y la pintura? ¿Alguno de nosotros que se considere incompetente en el dibujo puede recordar cuando fue la primera vez que alguien le inició de una manera sistematizada? Se trata de temas muy relacionados con las actuales formas de interpretar la inteligencia, de entre las cuales merece la pena destacar dos que podrían hacer cambiar la manera de entender los aprendizaje y la forma de promoverlos: A) La primera es que tanto el cerebro como los procesos cognitivos cambian a lo largo de la vida en función de las experiencias del sujeto, tanto por los campos en los que ésta tiene lugar como por la sutileza y profundidad de matices que tenga. Aquello que entrenamos desde temprana edad mejora exponencialmente. Aquello en lo que sobresalimos puede declinar si dejamos de practicarlo durante demasiado tiempo. Esto es muy interesante tanto para no infravalorar el potencial de niños diagnosticados con algún déficit, como para no sobrevalorar la sostenibilidad de la capacidad de un sobredotado, porque ambas cosas son variables a la luz de lo que sabemos actualmente. B) La segunda nos muestra que aprendemos haciendo asociaciones tanto neuronales como conceptuales, debajo de las cuales hay otras como las lingüísticas, auditivas, icónicas, y que hay cerebros más entrenados para unos campos que para otros, es lo que denominamos inteligencias múltiples asociadas de alguna manera a los diferentes lenguajes.

Como sistema de signos, la lectoescritura, con toda su antigüedad, supuso un gran avance cultural y tecnológico que ha de ser redescubierto de nuevo por cada niño que nace. En ella encontramos muchas de las ventajas que se les atribuyen a las tecnologías que empezaron a concebirse a mitad del siglo pasado: trata de representar la realidad, las ideas y los sentimientos; permite comunicarse a través del tiempo y del espacio sin necesidad de mostrar lo real; comunica unas mentes con otras en el plano intelectual, emocional y valorativo, es decir, genera repertorios de datos, ideas, explicaciones, respuestas emocionales y valorativas, que pueden trabajarse colaborativamente.

Al parecer, el cerebro se organiza de manera diferente según los diferentes sistemas de escritura, esto quiere decir que, por ejemplo, los lectores de chino e inglés no sólo utilizan diferentes circuitos cerebrales, sino que un mismo cerebro puede utilizar rutas diferentes para leer diferentes idiomas; y debido a la prodigiosa plasticidad del cerebro, el lector puede llegar a ser eficiente en todos ellos. Havelock $(1976,49)$ y Olson (1977) plantean la hipótesis de que la eficacia del alfabeto liberó a la gente del esfuerzo que requería la tradición oral o la de otros sistemas de escritura con mayor cantidad de signos y ello permitió disponer de más tiempo para el pensamiento propiamente dicho. A medida que los humanos fueron aprendiendo a utilizar la lengua escrita para

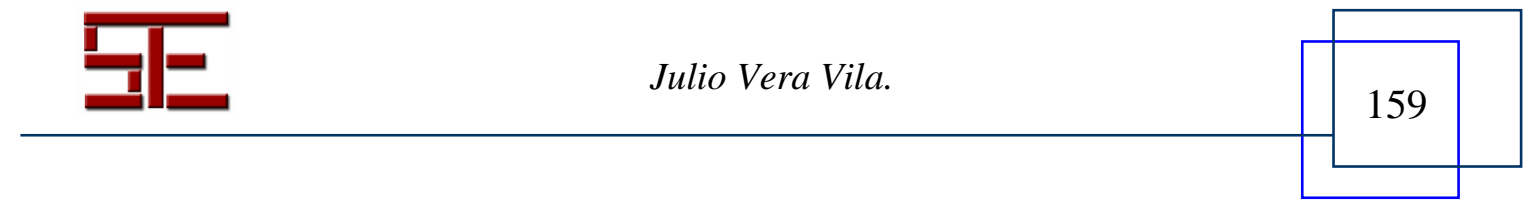




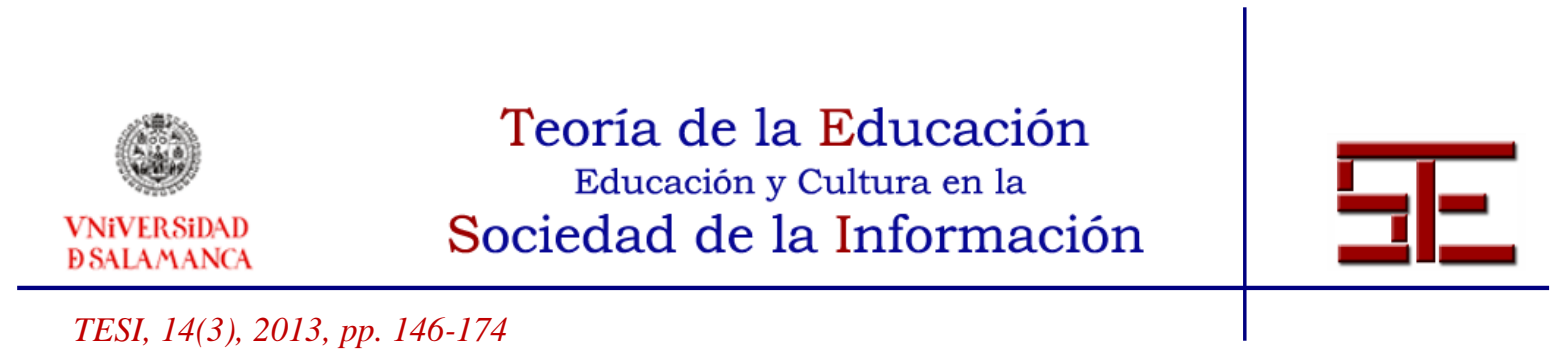

transmitir con precisión sus ideas, también se incrementó su capacidad para el pensamiento abstracto y las ideas novedosas (Vigotsky, 1962).

Todos estos conocimientos acerca de los procesos de adquisición humana de la escritura y la lectura nos ayudan en muchos sentidos: a) permiten valorar su importancia dado que en ellos están imbricados los sistemas de representación, los procesos de cognición con sus agregados emocionales, la imaginación, la memoria, etc; b) nos hacen conocer la importancia determinante de hacer estos aprendizajes desde el principio; c) nos ayudan a diseñar los mejores sistemas de enseñanza y a seleccionar las dimensiones que debemos incluir en ellos; d) nos invitan a suponer que lo que ocurre con los sistemas de representación lectores, pueden ser aplicados a otros como el matemático, el musical o el topográfico; e) nos exigen rigor respecto a lo que en la era digital debemos conservar y conjeturar qué otras cosas son novedades exclusivas de la era de internet; f) nos hacen comprender cómo las teorías científicas, en tanto que modelos de representación acerca del funcionamiento de una parte de la realidad, no son algo ajeno a la experiencia, sino que incluso son imprescindibles para generar un ámbito específico de experiencias difíciles de tener en poco tiempo sin su auxilio. Por lo tanto estudiar los procesos de creación de los sistemas primigenios de representación nos permite hacer extrapolaciones comparativas con los sistemas de representación más moleculares como son las teorías y paradigmas científicos. En definitiva nos permiten comprender mejor qué es el ser humano actual, cómo aprende y qué estímulos necesita para hacerlo con el menor coste de fatiga emocional y cognitiva.

Demasiadas veces nos olvidamos de hacer de los niños verdaderos nativos lectoescritores, mientras nos rendimos sin capacidad crítica alguna ante la supuesta evidencia de que son nativos digitales. Nadie nace acabado, somos nosotros los que los educamos a los niños de hoy en el contexto que les preparamos para aprender.

\subsection{Aprendizajes y carencias asociadas a los hipermedias e Internet}

Los términos "hipertexto" e "hipermedia" fueron acuñados por Ted Nelson en la segunda mitad de la década de los años 60 cuando trabajaba en su proyecto Xanadú. El proyecto consistía en construir un documento global único que contuviera todo el conocimiento existente mediante un sistema de enlaces. A este concepto de escritura ramificada y no lineal Nelson le denominó hipertexto y es la base del nacimiento de la red informática mundial (world wide web) que no es sino un sistema de distribución de información basado en hipertextos e hipermedias entrelazados a través de internet. Sus inicios se sitúan en los comienzos de la década de los 90. El concepto de hipermedia es una extensión del concepto de hipertexto en el que hay cabida para diferentes formatos y modos de representación, no sólo textos, sino también gráficos, imágenes, vídeos,

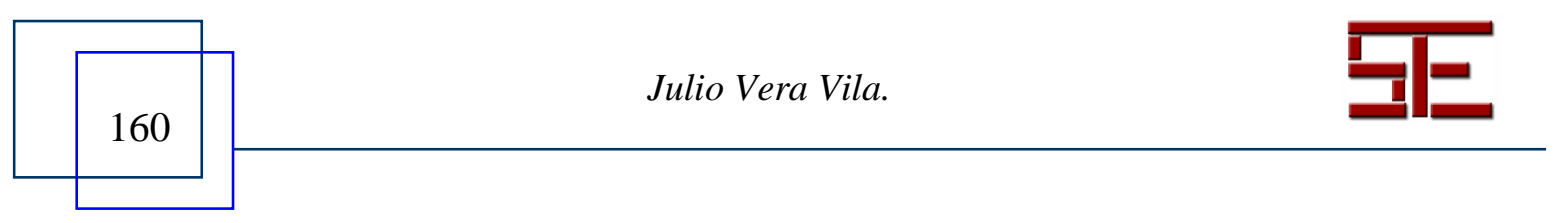




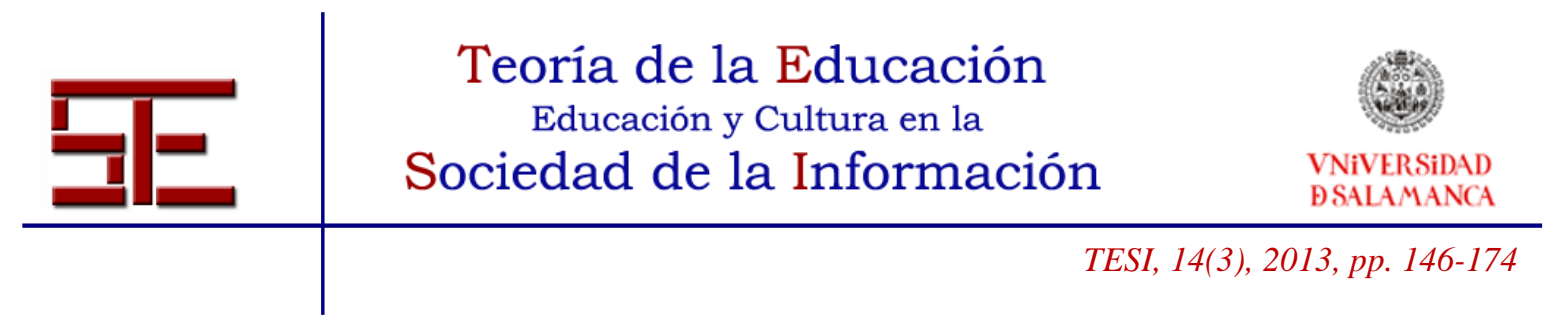

sonido y enlaces que vinculan unas informaciones con otras, lo que permite ir ampliando la información de manera progresiva (Kerckhove, 1999, 111).

Tim Berners-Lee (2000) dio un paso más. Su gran aportación no fue inventar algo nuevo, sino utilizar las herramientas ya disponibles -especialmente internet y los hipertextos- para crear algo mucho más importante de lo que cada una de las piezas significaba por separado. Internet era una infraestructura de comunicaciones que unía entre sí a los ordenadores. A partir de ahí la red podría ser un lugar para la comunicación mente a mente, un lugar en el que hacer, recibir, compartir, interactuar con otras personas o grupos con diferentes finalidades y niveles de alfabetización. Pensemos en las posibilidades que ofrece, por ejemplo, la realidad virtual que es una exteriorización de nuestras capacidades, pero a la vez el lugar en el que es posible tener nuevas experiencias compartidas con otras personas, con efectos tan reales como los de la realidad no digitalizada. El resultado es que en la actualidad un usuario puede acceder a la red mundial sin saber siquiera lo que es un formato, basta con saber utilizar uno de los muchos navegadores disponibles y aprender a manejarlo en menos de una hora. Toda la complejidad técnica de los lenguajes le aparecen en una página por la que se puede desplazar en modo totalmente reconocible, es lo que se denomina "interface" o interfaz.

Todo ello significa que de nuevo nos encontramos con que hemos ahorrado mucho tiempo en memorizar aquello que no debe perderse y hemos liberado otro para pensar y comunicarnos con personas interesadas en lo mismo que nosotros en cualquier parte del planeta. Pero todo tiene un límite, la red permite el contacto epidérmico y superficial con algo que queremos hacer o saber, también la dispersión más absoluta navegando sin sentido, o bien profundizar en un campo determinado del saber. Es lo que hace cada sujeto con el medio lo que determina los potenciales efectos que el medio tendrá en su cerebro, en sus sistema emocional y en su conciencia.

Las posibilidades que se abren para la enseñanza y el aprendizaje son muy grandes. Como señala Bernard (1993), el hipertexto podría ser considerado como la tercera dimensión de la lengua. El lenguaje no articulado, un grito, el llanto, sería el punto, la comunicación oral sería semejante a una línea, el texto escrito como una superficie y el hipertexto un espacio de tres dimensiones, un volumen que permite trabajar de otra manera en un nivel más potente. Como en toda transición, algo se pierde y algo se gana. La cuestión interesante es saber valorar lo que hemos ganado en esta transición y lo que no debemos perder de las anteriores.

El problema ahora no es el espacio, sino el tiempo. Podemos procesar más información que nunca pero sólo si dividimos nuestros períodos de atención en las múltiples tareas que podemos realizar con ella. El cerebro no puede procesar el texto a la velocidad de las imágenes en movimiento. La publicidad audiovisual nos acostumbró a pasar de puntillas sobre las cosas so pena de aburrirnos, pero aun en el supuesto de que eso fuera

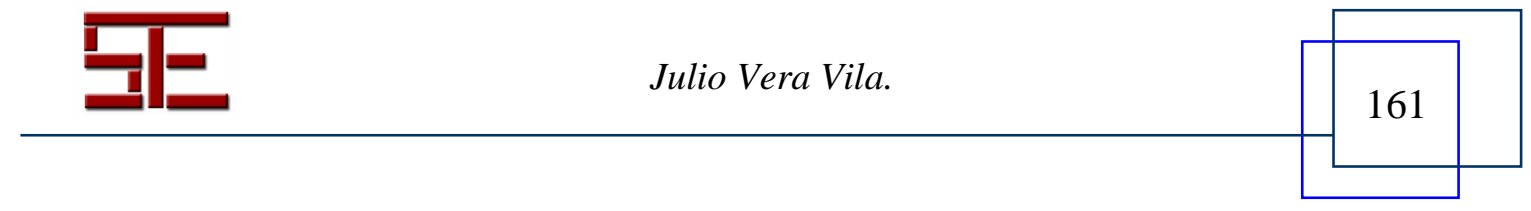




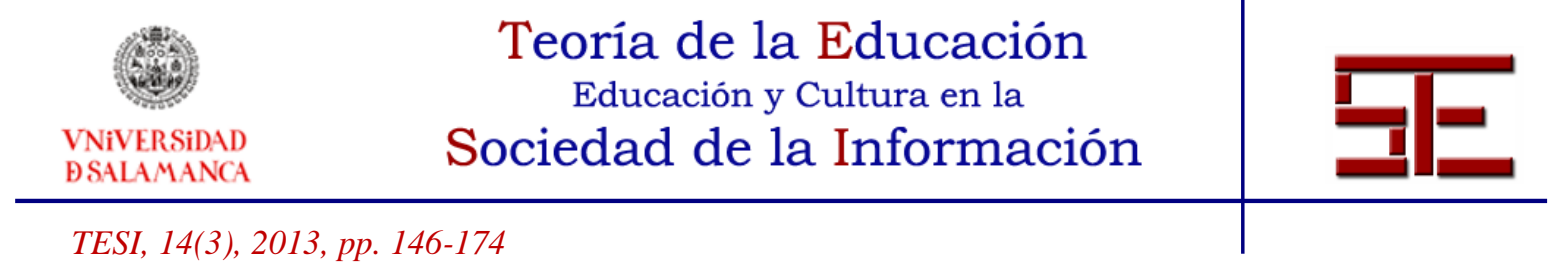

suficiente para comprender informaciones, la gramática, la literatura, el estilo, se pierden. A pesar de que los hipermedia contienen una gran cantidad de información que puede ser trabajada con detenimiento a gran profundidad, en otro sentido y para otros fines, las unidades de información han encogido para ser procesadas muy rápidamente como eslóganes, carteles, portadas, logos, muletillas, titulares, etc. Ahora convive la información profunda con la minimalista, de manera que es muy fácil crear la impresión de que se sabe cuando tan sólo se ha rozado la epidermis de las ideas aderezada con opiniones de discutible valor. Cada cosa puede tener su sentido y su utilidad, pero todo no vale para todo.

\subsection{Hacia una alfabetización integral}

El cerebro humano conectado a Internet es capaz de desarrollar un número infinitamente superior de conexiones que sin él. Todavía sabemos poco acerca de los efectos y el impacto que está teniendo el uso de internet en nuestro cerebro, pero cabe pensar que es muy importante en función del uso que se haga de él (Carr, 2011).

¿En qué debe centrarse la educación de este siglo? ¿Cuál es el concepto de cultura básica y cual el de cultura sostenible que debemos defender en un mundo en constante cambio, en una realidad donde el hardware y el software cambian y quedan rápidamente obsoletos, donde las grandes creencias sucumben a los pensamientos líquidos? ¿Qué necesita el cerebro para seguir funcionando libre, crítico, independiente y empático? Cuando podemos hacer tantas cosas, el problema es delimitar qué queremos hacer y qué debe ser hecho: la vuelta a la búsqueda de sentido, la vuelta a los valores.

Nada impide preservar la dimensión constructiva de la lectura de los niños sin renunciar a sus crecientes aptitudes para realizar múltiples tareas y para asimilar grandes cantidades de información en permanente expansión. Por ello, deberíamos empezar a proporcionar una formación explícita para leer las diversas modalidades de presentación de textos, a fin de garantizar que aprenden múltiples maneras de procesar la información. En principio lo razonable es tratar de no perder ni las competencias de la oralidad, ni las de la escritura porque mejoran las nuevas de la era digital. Parece claro que debemos valorar y proteger la alfabetización alcanzada hasta ahora y trabajar para que a partir de lo aprendido, nuestro cerebro sea capaz de adquirir nuevas competencias. No necesitamos escoger entre diferentes modalidades de comunicación, pero no debemos perder la profunda capacidad generativa del cerebro lector mientras añadimos nuevas posibilidades a nuestro repertorio intelectual. La lectura e internet no son alternativas, son piezas de un mismo proceso de adquisiciones que se alimentan y se sostienen las unas en las otras (Wolf, 2008, 33). Nuestro problema es priorizar en cada etapa de la biografía del sujeto, establecer un orden en los aprendizajes a adquirir,

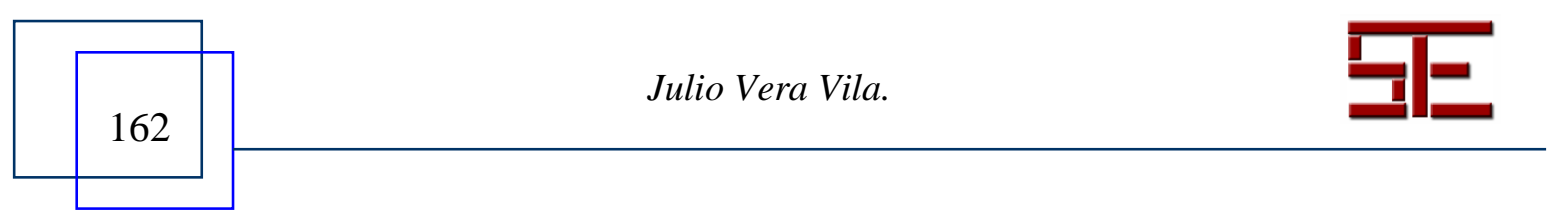




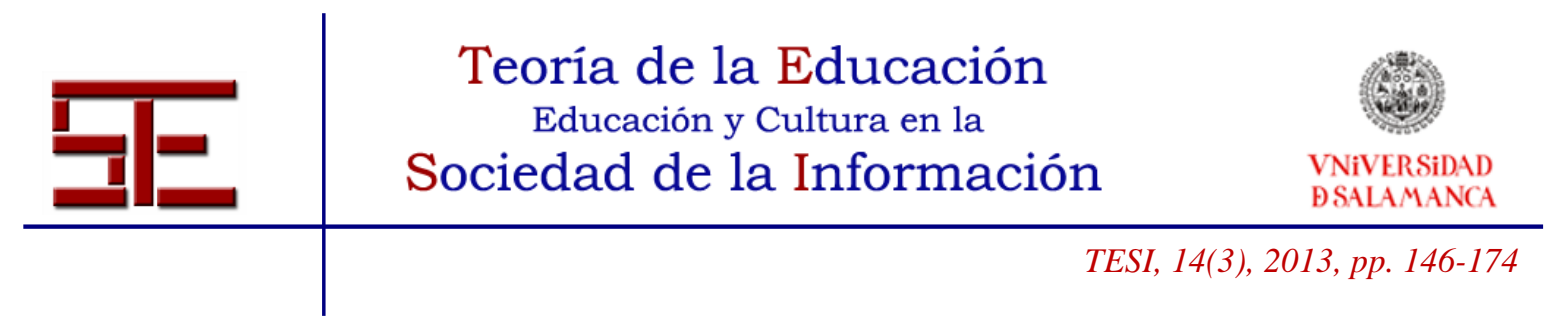

seleccionar los contenidos en los que pensar y decidir las herramientas que emplearemos en cada circunstancia.

Puede que muchos de esos niños que saben acceder a internet con muy poco esfuerzo apenas sepan pensar por sí mismos y es posible que sus miradas se vayan estrechado a lo que ven y oyen sin esfuerzo, si nadie les estimula a explotar la mayor ventaja del cerebro lector: el tiempo para pensar por su cuenta. El libro es uno de los lugares en los que las palabras pueden descansar, cuando hablamos o cuando nos movemos por las pantallas casi siempre están en movimiento. La palabra impresa permite ralentizar el tiempo al ritmo de lectura y hay ideas que por su complejidad requieren ser releídas, analizadas, comparadas con otras, contrastadas, compartidas. Incluso en esta era digital hay ideas que merecen ser fijadas en aquella forma que permita su análisis detenido (Kerckhove, 1999, 143-144). Cuando toda la información está disponible todo el tiempo, lo que le da valor es la capacidad de búsqueda, selección y análisis. Es ese trabajo de análisis de la información la que le da valor y posibilidad de mejora, ampliación o transformación. Los libros fueron en su momento aceleradores y difusores del conocimiento, en cambio ahora son ralentizadores en comparación con la velocidad a la que navega la información por internet. Ellos permiten pensar y convertir el pensamiento en conocimiento utilizable para el progreso humano. Además, la lectura reposada y atenta es más resistente a la manipulación, al adoctrinamiento y a las modas, permite que cada lector goce de libertad para seguir el curso de sus propias ideas, en función de sus necesidades y para sus proyectos personales. Es difícil esperar que el lector hipertextual e interactivo sea competente sin antes haber sido un buen lectoescritor entrenado en las competencias intelectuales porque el vínculo principal de la red de redes debe ser cada usuario, que es quien decide lo que debe hacer en función de su grado de alfabetización. Los educadores deberían entender que los libros no van a ser sustituidos por ninguna otra tecnología. "Todos deberíamos darnos cuenta de que no pueden desaparecer, que es crucial mantener la presencia de los libros no sólo como tecnologías para el procesamiento de la información, sino como tecnologías del ser" (Kerckhove, 1999, 157).

\section{SABIDURÍA DIGITAL Y CONECTIVISMO}

\subsection{Más que nativos e inmigrantes: alfabetizados $u$ olvidados}

El concepto de nativo digital es muy gráfico, pero engañoso si no tenemos en cuenta que todos los jóvenes a los que alude ese término son también nativos lectoescritores a los que les cuesta aprender a leer y escribir con fluidez. El mismo Prensky enriquece y mejora sus propuestas iniciales -nativos e inmigrantes- al introducir el concepto de sabiduría digital que trasciende la brecha entre inmigrantes y nativos ya que "muchos inmigrantes digitales exhiben hoy esa sabiduría digital” $(2011,96)$ ¿Quienes son sabios

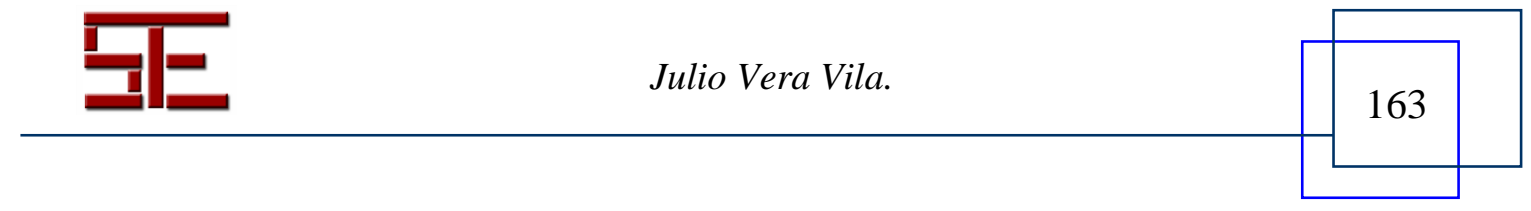




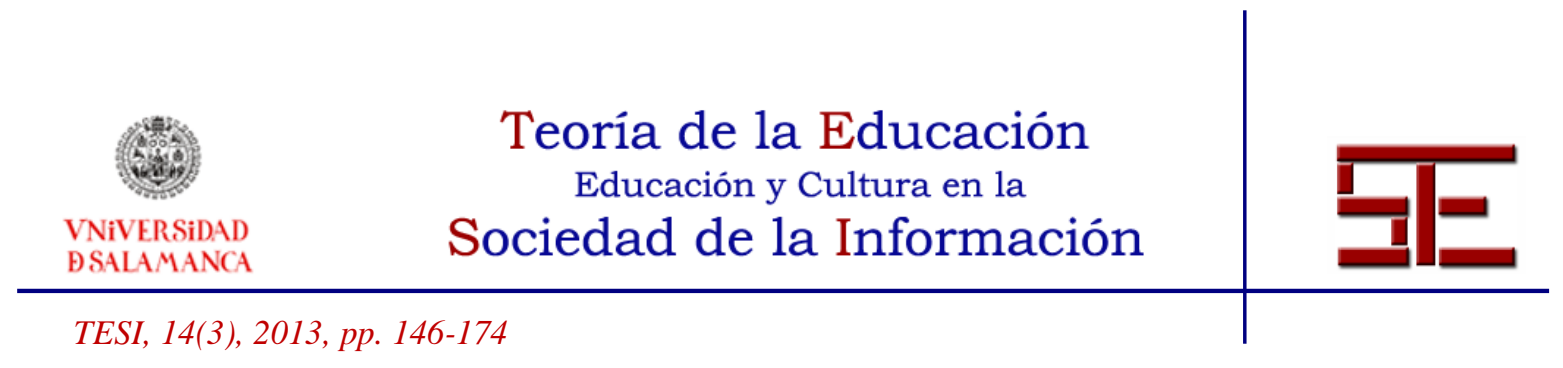

digitales según Prensky? "Los que inteligentemente combinan lo innato con las herramientas digitales que estén a su alcance" (Ibid, 97). "Ser sabio digital implica no sólo mejorar nuestras capacidades naturales con las tecnologías existentes, sino también identificar continuamente áreas adicionales. Investigar y evaluar tanto los aspectos positivos como los negativos de las nuevas herramientas, y la forma de lograr el equilibrio que las convierte en herramientas potenciadoras de la sabiduría" (Ibid, 103).

Lo que viene a decir Prensky es que puesto que el mundo exterior forma parte de lo que somos, puede decirse que pensamos con los libros, las computadoras, los teléfonos móviles, Internet, etc. Para una gran parte de la población mundial su ecosistema natural no tiene fronteras ni límites físicos. Nuestras barreras son hoy fundamentalmente interiores y están constituidas por los límites de lo que sabemos y de lo que ignoramos, es decir de nuestro grado de alfabetización. Cuanto más alfabetizados estemos en los diferentes sistemas de signos, más y mejor podremos hacer uso de las memorias externas que son de experiencias cognitivas, sentimentales y morales (Vera, 2007). Así pues todas las tecnologías en las que hemos sido alfabetizados y que podemos utilizar para plantear y resolver problemas son susceptibles de formar nodos y enlaces con nuestra red de pensamientos y aprendizajes, sean cognitivos o no. Nuevamente nos encontramos con la idea de sistema, de redes (teoría de sistemas) y de conexiones probables, inciertas, aleatorias y de resultados imprevistos (teoría del caos), en este caso entre nuestro pensamiento y las tecnologías. El nodo principal en la red, a efectos educativos, es siempre el usuario y lo que haga en y con ella, por eso debe ser alfabetizado y educado. Cuando pensamos que algo es innato tendemos a no educarlo y ese es el mayor peligro del concepto de nativo digital y de interpretarlo de manera muy diferente al de nativo lectoescritor. Todo niño tiene derecho a ser educado y, por lo tanto, a nacer en un contexto rico en lectoescritura y en nuevas tecnologías.

\subsection{El conectivismo. Una manera integrada de comprender el aprendizaje a través de los lenguajes}

Si el concepto de sabiduría digital evoca la necesidad de relación entre los procesos cognitivos y las tecnologías, el conectivismo es una forma de explicar los procesos de aprendizaje en un entorno humano en el que las tecnologías digitales son parte del mismo. Se trata de una teoría que trata de dar cuenta de los comportamientos, actitudes, supuestos, valores con los que actúan las personas cuando su hábitat incluye lenguajes, soportes y contextos digitales. La cuestión fundamental radica en que forma parte de nuestras experiencias cotidianas el estar en conexión con otras personas que al igual que nosotros utilizan las tecnologías digitales y al igual que nosotros saben algunas cosas e ignoran muchas otras. Cuando tenemos que obtener información o resolver un problema ya no disponemos de reglas fijas que nos den ni la mejor información, ni tampoco la solución adecuada, entre otras cosas porque para determinadas cuestiones complejas

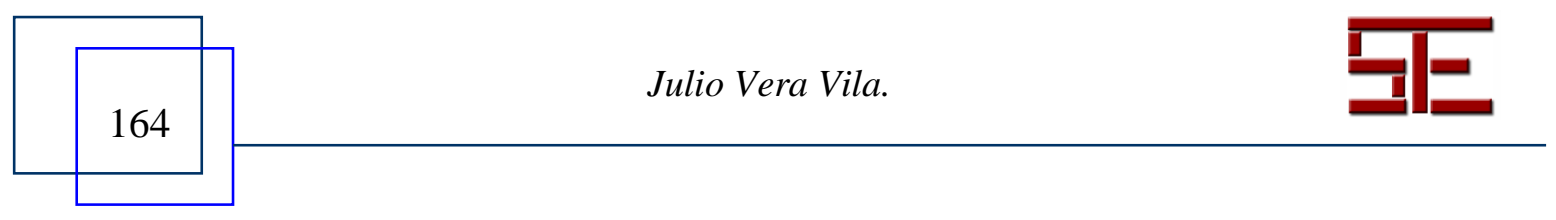




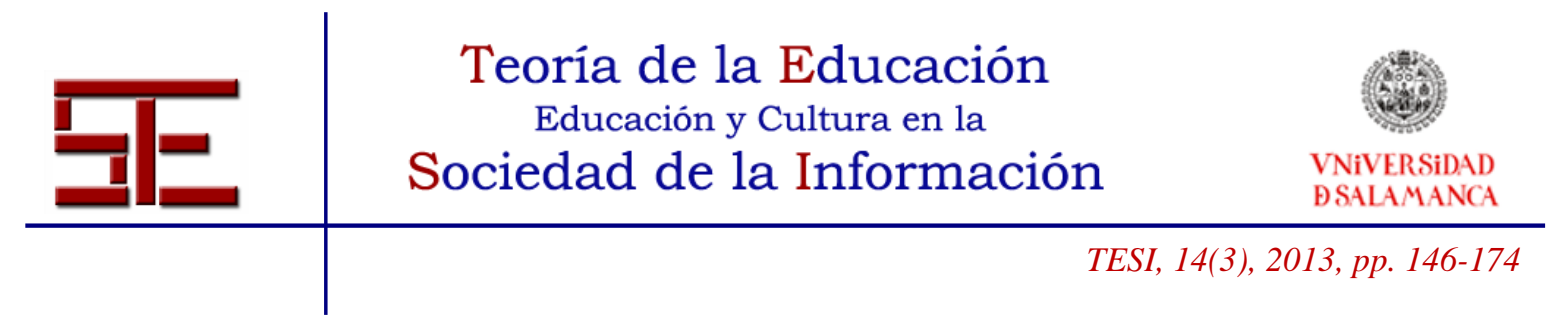

puede haber varias soluciones alternativas a sopesar con buen juicio (teoría del caos), por ello debemos recurrir a bases de datos de otras personas o que estén disponibles en cualquier soporte, por ejemplo en Internet. Esto se traduce básicamente en que el aprendizaje es, entre otras cosas, un proceso de conexión de nodos o fuentes de información especializados. En las propias palabras de George Siemens (2011, 84-85) "El conectivismo es la integración de principios explorados por las teorías del caos, redes, complejidad y auto organización. El aprendizaje es un proceso que ocurre en el interior de ambientes difusos de elementos centrales cambiantes -que no están por completo bajo el control del individuo-. El aprendizaje (definido como conocimiento aplicable) puede residir fuera de nosotros (en el interior de una organización o una base de datos), está enfocado en conectar conjuntos de información especializada, y las conexiones que nos permiten aprender más tienen más importancia que nuestro estado actual de conocimiento". Por ello, el punto de partida del conocimiento está en el individuo, en su propia red de conocimientos que se comparten con otras personas en red y pueden servir para que las organizaciones aprendan. En ese círculo el conocimiento puede mejorar, corregirse, ampliarse y retroalimentarse como algo permanente y vivo. Lo bueno de cualquier aprendizaje es poder disponer de él cuando la situación lo requiere, pero como eso no siempre es posible, la habilidad para saber localizar las fuentes en la que encontrar lo que necesitamos y conectar con ellas es hoy una habilidad vital en el doble sentido, en el sentido de su importancia y en el sentido de su cotidianidad.

\section{HACIA UNA TEORÍA DE LA EDUCACIÓN Y UNAS PRÁCTICAS EDUCATIVAS DE LA COMPLEJIDAD}

\subsection{Acerca de la teoría}

Se cumple ahora algo más de una década de la publicación de un libro muy estimulante y clarificador para todos los que nos dedicamos a la Teoría de la Educación. Me refiero a "La (de) construcción del conocimiento pedagógico. Nuevas perspectivas en teoría de la educación (Colom, 2002). A mi entender es uno de los esfuerzos más sólidos por tratar de comprender los fenómenos educativos en toda su complejidad actual de manera que sea posible hacer unas prácticas educativas complejas (caóticas) sin caer en la desorientación, en el todo vale o cuanto peor, mejor.

¿Pero qué es la complejidad? La complejidad no es complicación. En la ciencia positivista, las contradicciones se consideran un error, en la teoría de la complejidad no son tales, sino la constatación de que hay capas profundas de la realidad que no pueden ser traducidas, al menos de momento, a nuestra lógica. Cuando queremos reducir la realidad a sólo aquella parte de la misma que puede ser traducida en términos empíricoracionales, lo que estamos haciendo es apartar la parte compleja e inexplicable de la

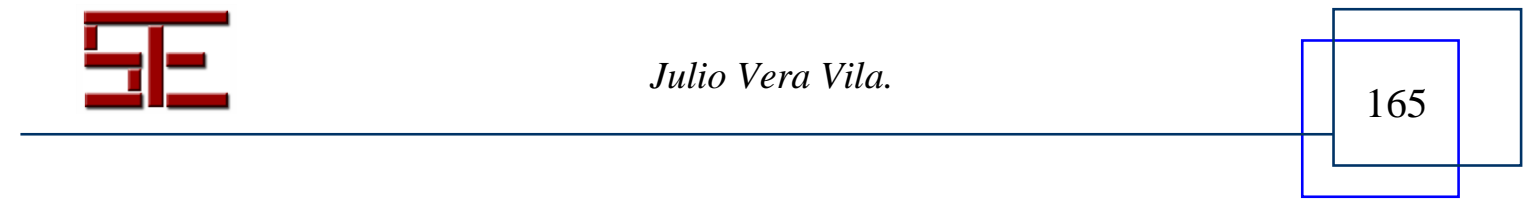




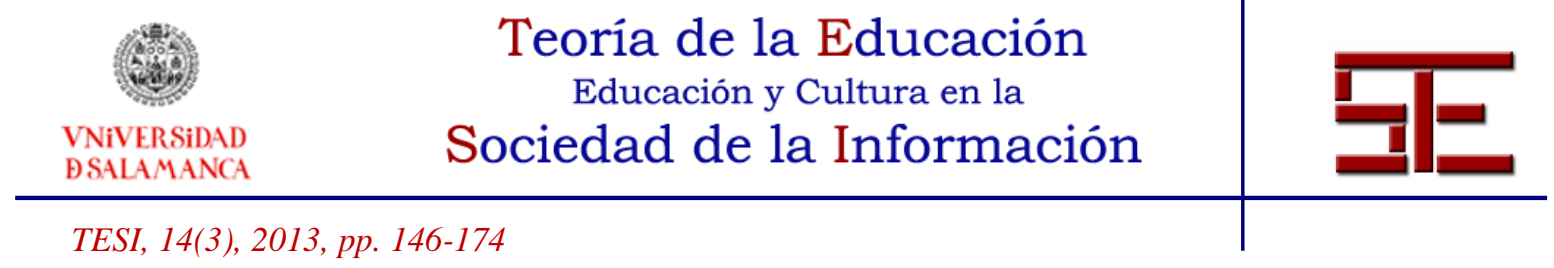

realidad de nuestro modelo teórico. A veces es preferible contentarnos con conocimientos parciales obtenidos en situaciones sencillas, porque esos datos nos son útiles, son conocimiento, pero siempre y cuando admitamos y demos cabida a esas otras partes que todavía no podemos comprender (Morin, 2002, 41).

Los sistemas complejos son dinámicos en el sentido de que son extremadamente sensibles a sus condiciones iniciales, de modo que alteraciones muy pequeñas en sus causas son capaces de producir grandes efectos. Como consecuencia de ello no es posible predecir con exactitud cómo se comportarán esos sistemas con el tiempo. En estos sistemas el orden existe pero no es absoluto ni incondicional, sino relativo y contingente porque depende de sus condiciones de aparición, de existencia y continuación. La incertidumbre se convierte entonces en un elemento más de la explicación científica de esos sistemas, que como el ser humano, son complejos.

"El pensamiento complejo está animado por una tensión permanente entre la aspiración a un saber no fraccionado, no dividido, no reduccionista y el reconocimiento de lo inacabado e incompleto de todo conocimiento" (Ibid, 2002, 49). La certidumbre generalizada es un mito, sólo podemos tener certidumbres relativas sobre parcelas de la realidad. El pensamiento complejo utiliza la simplificación pero al mismo tiempo es consciente de su insuficiencia para captar la multidimensionalidad. Aquello que es complejo admite la incapacidad para lograr certezas absolutas o concebir un orden absoluto y reconoce además la incapacidad para evitar contradicciones (Morin, 1994, 99).

El paradigma de la simplicidad es un paradigma que pone orden en el universo reduciéndolo a una ley o a un principio. Toda visión especializada, parcial, unidimensional es pobre. "Mientras el pensamiento simplificador desintegra la complejidad de lo real, el pensamiento complejo integra lo más posible los modos simplificadores de pensar, pero rechaza las consecuencias mutilantes, reduccionistas, unidimensionales y finalmente cegadoras de una simplificación que se toma por reflejo de aquello que hubiera de real en la realidad" (Morin, 2001a, 22). En este sentido el pensamiento complejo aspira al conocimiento multidimensional, pero sabe desde el principio que el conocimiento completo es imposible. La ambigüedad, la incertidumbre, la dinámica, el cambio, la impredictibilidad, el orden, el desorden, la auto-organización forman parte de los sistemas dinámicos y complejos como el ser humano.

"Todo conocimiento constituye a la vez una traducción y una reconstrucción, a partir de señales, signos, símbolos, bajo formas de representaciones, ideas, teorías, discursos" (Ibid, 29). El proceso es circular, necesitamos esquemas generales de comprensión que provisionalmente nos ayuden a integrar los datos que obtenemos parcialmente y, a la vez, necesitamos analizar aspectos muy concretos de la realidad para construir saberes mutidimensionales. Los símbolos se articulan en lenguajes, los lenguajes nos ayudan a tener ideas, las ideas se articulan en razonamientos y así en sucesivos procesos de

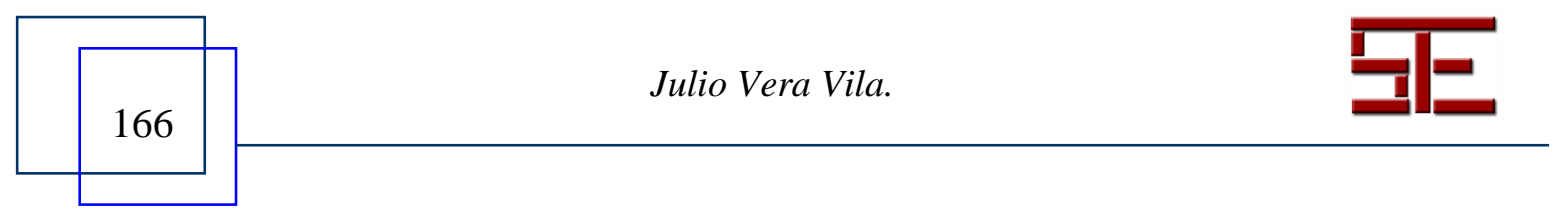




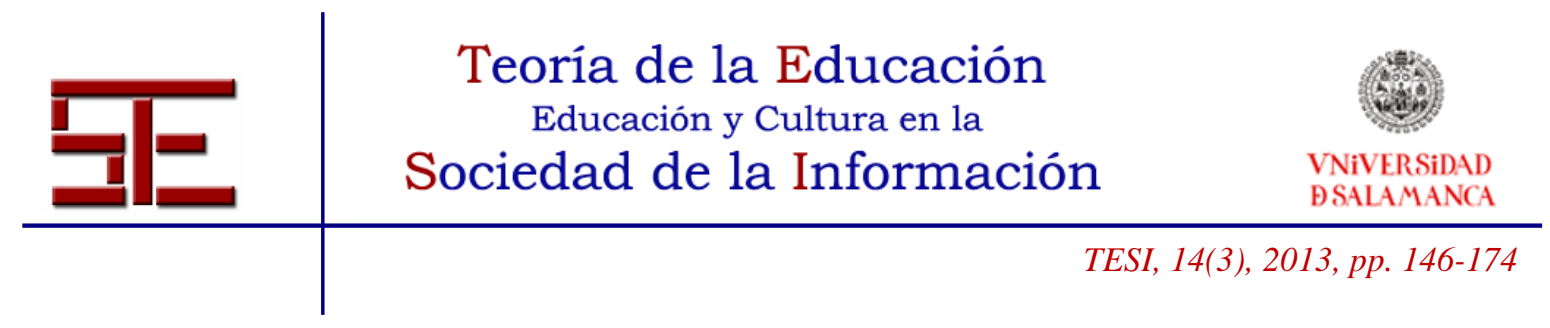

análisis y síntesis entre lenguajes, pensamientos y modelos teóricos. La psicología cognitiva nos enseña que el conocimiento progresa por integraciones comprensivas de conocimientos singulares. El conectivismo nos permite entrelazar saberes de diferentes campos o dimensiones de la vida y en ese sentido se adapta bien a la complejidad vital como la teoría de sistemas o la teoría del caos. A partir de entonces, como señala Morin (2001, 30), "el desarrollo de la aptitud para contextualizar y globalizar los saberes se convierte en un imperativo de la educación". La educación debe tratar de convertir la información en conocimiento y el conocimiento en sabiduría acerca de la condición dinámica, abierta y cambiante de la vida. En sistemas complejos nunca podremos predecir cuánto es capaz de mejorar un semejante cuando le damos una pequeña ayuda, ni cuando ésta tendrá efecto, ni si en adelante le será suficiente para gobernarse a sí mismo con una cierta dignidad.

Daniel Pennac nos narra de forma literaria la recompensa de los profesores que no desfallecen tratando de rescatar a los zoquetes con cariño, convicción y búsqueda de estrategias. Todos en algún momento y en algún área somos transitoriamente zoquetes esperando ser alfabetizados y rescatados. El peor vaticinio para una persona es creer que no tiene futuro; el de cualquier ignorancia, creer que no puede ser superada; el de cualquier déficit, el pensar que no podrá ser compensado; el de los daños irreparables y profundos, que no tendrá el auxilio afectuoso y atento de quienes le rodean. "Los profesores que me salvaron $-y$ que hicieron de mí un profesor- no estaban formados para hacerlo [...]. Eran adultos enfrentados a adolescentes en peligro. Se dijeron que era urgente. Se zambulleron de nuevo, día tras día, más y más... Y acabaron sacándome de allí. Y a muchos otros conmigo. Literalmente, nos repescaron. Les debemos la vida" $(2008,36)$.

La educación, ya sea considerada como proyecto, como proceso o como resultado; ya la pensemos en su dimensión personal o social, es un sistema hipercomplejo, en el que intervienen multitud de elementos y un alto grado de imprevisibilidad. Lo caótico, nos dice el profesor Colom (Cfr. 1982-194), no son los elementos del sistema sino la complejidad de las relaciones que se establecen entre los múltiples elementos que intervienen en el funcionamiento del mismo. La educación es un sistema abocado al caos, o si se prefiere, a lo imprevisible, al cambio permanente, a la constante retroalimentación, reestructuración y equilibración, por la cantidad de variables que intervienen y las muchas relaciones que pueden darse entre ellas.

La teoría del caos nos da una comprensión de los fenómenos educativos en tanto que procesos no lineales, abiertos, conectables, colectivos, que manejan una información en mosaico al modo de los hipertextos, lo que propicia hacer del aprendizaje un acto de descubrimiento creativo y colaborativo. La propuesta del profesor Colom consiste en formular la teoría de la educación actual en los mismos términos en los que las personas (nativos o migrantes digitales) estamos impelidos a aprender hoy en día, es decir,

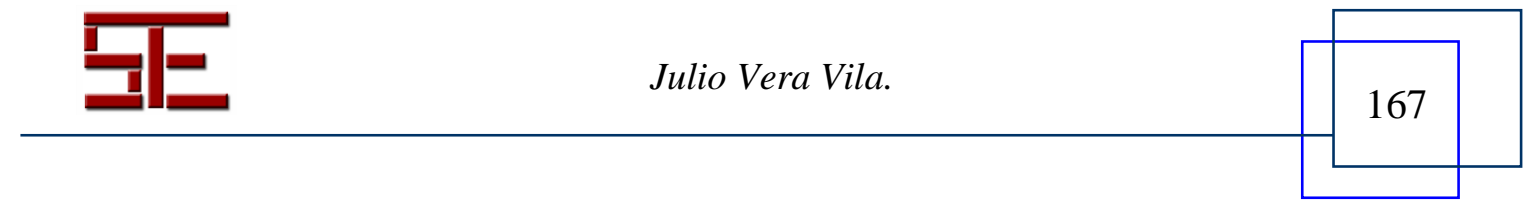




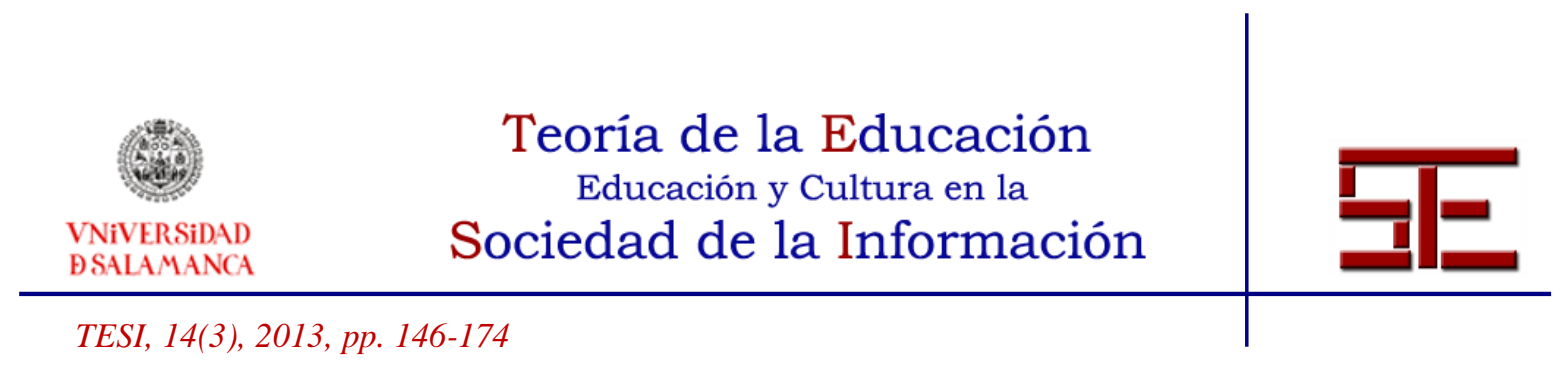

interpretando y ordenando el conocimiento desde la complejidad, usando las tecnologías disponibles y en colaboración con los demás. La metáfora que utiliza reiteradamente para poner ejemplos de prácticas educativas complejas es la del laberinto, también la del hipertexto, desde mi punto de vista, porque ambos reclaman: a) operatividad cognitiva por parte del que aprende (buscar, analizar, seleccionar, sintetizar, valorar, contrastar, cotejar, compartir, corregir, etc.); b) diversidad de fuentes, lenguajes, recursos multimedia y tecnologías para trabajar con la información y c) proyectos educativos compartidos por profesores lo mejor preparados que sea posible pero interesados en su trabajo.

Para que todas las herramientas didácticas situadas en la red tengan viabilidad y sentido pedagógico en el aula, es imprescindible la figura del docente, con una correcta formación no sólo técnica, científica e instrumental, sino, también pedagógica y humanística. Por lo tanto, las TIC, no deben ser concebidas como un fin para dar soluciones automáticas a los problemas que se planteen en contextos educativos, sino en su triple dimensión de contenido, herramienta y contexto, que favorecen los procesos de enseñanza y aprendizaje cuando están enmarcados en proyectos educativos valiosos y bien fundamentados, sólo entonces las TIC se transforman en TACs (Vera, 1997).

\subsection{Consideraciones sobre las prácticas}

La teoría de la educación siempre ha tenido en el orden y la linealidad su razón de ser, lo que le ha permitido tener un discurso coherente. Sin embargo, estos planteamientos a veces excesivamente simplificadores no han dado cuenta de los ruidos educativos (fracasos, singularidades, conflictos, desigualdades, supuestas discapacidades o sobredotaciones, etc.), por lo que muchas veces, aunque existen son obviados en la narratividad que trata de comprender lo que ocurre y cómo se debería actuar en la práctica.

Por lo tanto ¿cómo ha de ser la práctica educativa? Si aceptamos la hipercomplejidad del hecho educativo, las enormes diferencias en el punto de partida (biológicas, psicológicas, sociales, culturales, económicas, biográficas...), la aleatoriedad de los resultados previstos, lo que no podemos es buscar recetas simples. Hay prácticas específicas para aprendizajes muy concretos cuyos pasos pueden precisarse. Por ejemplo: memorizar datos concretos, escribir a máquina, aprender a usar el ordenador, medir algo, localizar un accidente geográfico en un mapa, y otras. Pero todos esos aprendizajes son de carácter instructivo y la educación es bastante más que eso, exige comprender, relacionar datos, articular explicaciones, hacer extrapolaciones a contextos diferentes, dominar diferentes lenguajes, manejar y expresarse con diferentes medios, etc. En definitiva, la educación del ser humano es un proceso siempre inacabado en el que están presentes elementos de muy diferente tipo. No se puede acceder a

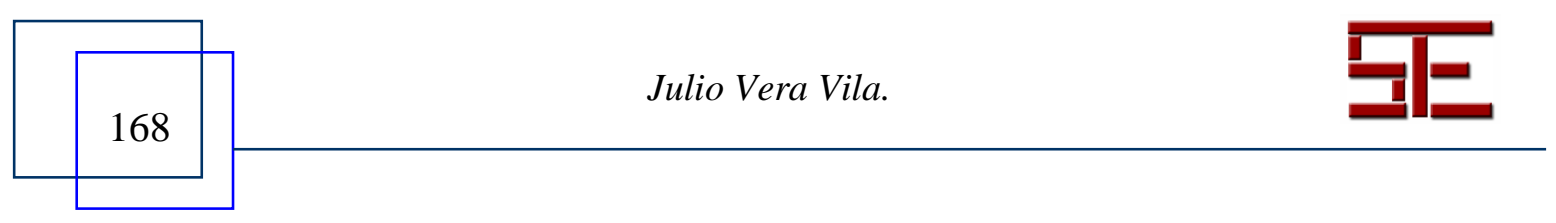




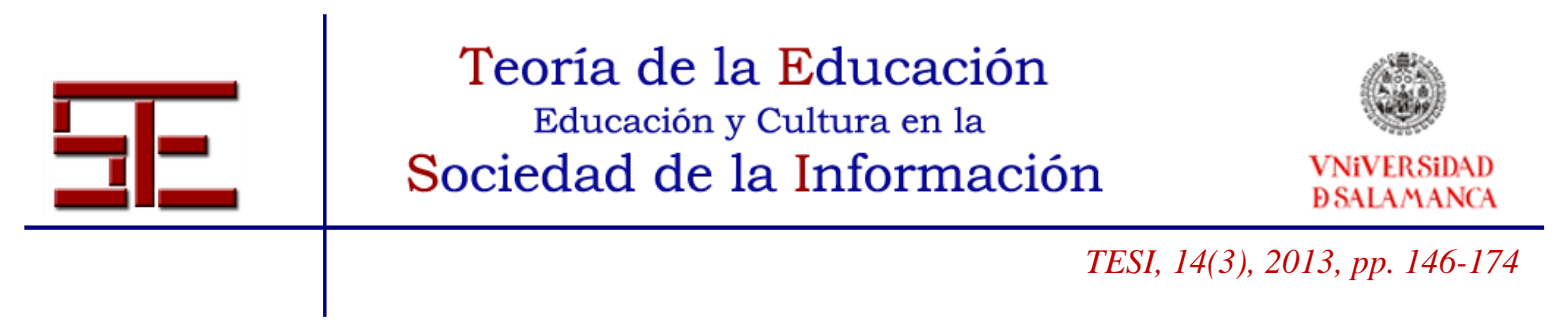

aprendizajes complejos a través de recetas simplistas sino con prácticas que incorporen la complejidad, la incertidumbre, la interdisciplinariedad y el error como elementos del proceso. Todo aprendizaje adquirido procede de una fase de desorden, ignorancia, tanteo, insuficiencia, en definitiva de cierto caos. La esencia del propio proceso educativo se asienta en lo inacabado, en la inmadurez, en la necesidad de acceder a mayores cotas de formación. La educación, por lo tanto, no es un estadio al que llegar, sino un proyecto evolutivo, abierto, inacabado, inestable, dinámico, cambiante e incierto. Educar es tratar de acotar esas incertidumbres caóticas (Colom, 2002, 174).

Si los aprendizajes humanos, sobre todo los más elevados, son complejos; las prácticas educativas que los propicien difícilmente pueden ser simplificadoras ni simplistas. Si la sociedad es altamente cambiante, hemos de educar en la incertidumbre porque aunque tenemos certezas sobre algunas cosas, la comprensión de conjunto es cada vez más difícil y provisional (Morin, 2001b). Explicitar con detalle la forma de articular prácticas educativas de la complejidad en las que estén implicados los lenguajes y las tecnologías de la información exigiría más espacio del aquí disponible, pero al menos sí merecerá la pena sugerir algunos principios a tener en cuenta.

a) En principio no cabe pensar en unas prácticas específicas de la complejidad sino más bien de enfoques o puntos de partida desde los que explicitar la complejidad que todo encierra bajo la apariencia de simplicidad. Cuanto más nos detenemos a estudiar algo más nos apercibimos de lo insuficiencia de nuestro conocimiento y de las aristas del problema. Por ejemplo, una búsqueda de información a través de internet puede simplificarse yendo directamente a una sola fuente (la wikipedia), puede hacerse muy confusa navegando por enlaces sin una idea preconcebida o puede convertirse en algo muy formativo si se van estableciendo y adquiriendo criterios de búsqueda. Hacer un dibujo puede hacerse improvisando sin reglas ni reflexión, lo cual puede ser coherente con ciertos objetivos, o bien puede conllevar un proceso de descubrimiento de las técnicas que se han ido desarrollando para incluir tonalidades, volumen, luces y sombras, contornos, significados culturales, originalidades de autor y herramientas disponibles según la época. Una práctica educativa no es inovadora por el mero hecho de usar las nuevas herramientas tecnológicas, sino, en todo caso, por la manera en que al hacerlo potencian aprendizajes valiosos en los que siempre está implicado el dominio de algún lenguaje.

b) La práctica educativa no puede quedarse en la parcelación de la realidad por campos específicos del saber, ni reducirse al conocimiento de lo más simple, sino que debe progresar hacia niveles de complejidad creciente. Saber algo debe implicar la comprensión, en algún nivel, de la relación entre todas sus dimensiones, ya sean artísticas, lingüísticas, arquitectónicas, físicas, geográficas, históricas, espirituales o cualesquiera otras. Cuando se acaban las matemáticas y comienza la hora de lengua, la realidad y el observador siguen siendo los mismos. Esta línea de continuidad de lo real

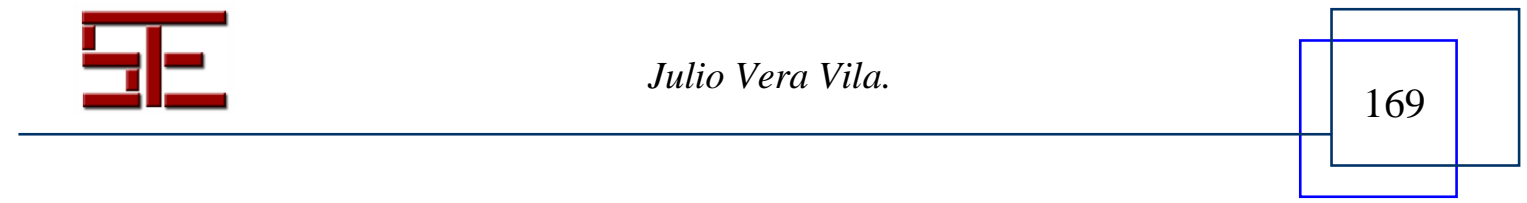




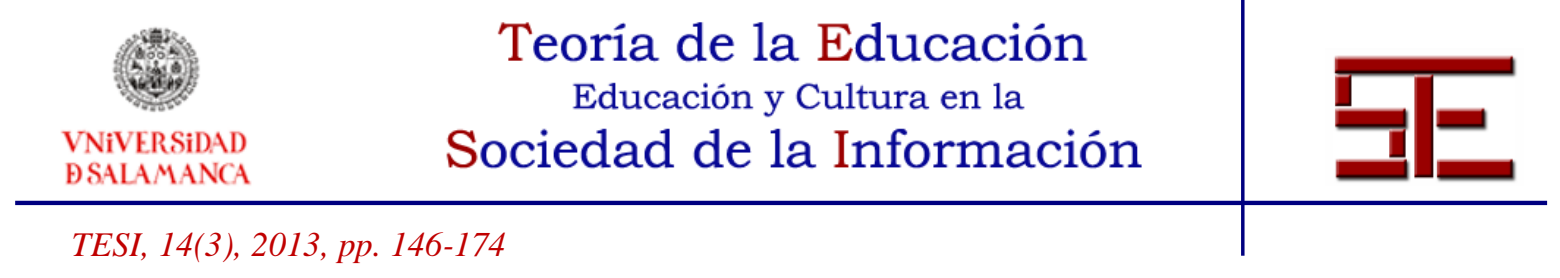

y las múltiples dimensiones que puede analizarse en cualquier hecho es más fácil de visualizar con el uso de los recursos hipermedia.

c) La práctica educativa debe romper con los estereotipos acerca de los alumnos y sus capacidades de aprendizaje (tanto los catalogados como discapacitados como los denomidados sobredotados) y admitir que todas las personas tenemos circunstancias de partida diferentes y un nivel de desarrollo potencial cuyos límites desconocemos. Debemos educar con la convicción de que, aparte de los condicionantes genéticos, todo va a depender del apoyo y el estímulo que recibamos tempranamente, de la formación adquirida y de lo estimulante que sea el contexto próximo. Esto es especialmente importante en relación a la necesidad de alfabetizar en los diferentes lenguajes, usando diferentes tecnologías y tratando de incidir en todas las inteligencias, incluida la emocional (interpersonal e interpersonal). Cada alumno puede llegar al mismo sitio por caminos diferentes o a sitios diferentes usando los mismos recursos. En esta aparente paradoja están basados los hipertextos con sus nodos y enlaces. Ya hemos dicho que el nodo fundamental de todos los elementos implicados en el aprendizaje es el alumno, lo que hace, siente, piensa en relación con los demás.

d) Cualquier práctica educativa debería tener en cuenta que la adquisición temprana de los viejos lenguajes es la base para el desarrollo de la capacidad de pensar, relacionarse y usar las tecnologías disponibles más allá de su consumo acrítico. En especial los hipermedia permiten hacer, crear y a la vez reflexionar acerca de actividades educativas complejas. Hay que aprovechar la predisposición positiva de los más jóvenes hacia lo tecnológico para mejorar sus competencias en el manejo y aplicación de las mismas.

e) Las situaciones de aprendizaje deben partir de alguna temática o situación que implique complejidad, es decir, que obligue a detectar problemas o áreas de curiosidad, a buscar información, a analizarla, a organizarla, a trabajarla cooperativamente, a exponerla usando diferentes lenguajes y medios tecnológicos. Esto significa poner en segundo plano los contenidos culturales sistematizados y sintetizados, porque ellos han de ser la conclusión del esfuerzo y la pasión por aprender, no su origen, que sería artificial y engañoso. La temática ha de ser algo realmente interesante para los alumnos, algo en lo que sean capaces de implicarse emocionalmente, más adelante ya irán descubriendo todas sus implicaciones y relaciones con otras dimensiones de lo real. Cualquier cosa es tan simple o tan compleja como seamos capaces de analizarla. Una letra es una letra, pero las letras cambiaron el mundo y nuestra capacidad para analizarlo.

f) El alumno ha de reconstruir, en la medida de sus posibilidades en cada momento de su desarrollo, el camino del investigador que se enfrenta por primera vez a un problema: definir los objetivos, establecer un plan de trabajo, gestionar y compartir su puesta en práctica y exponer unas conclusiones, por supuesto siempre con el acompañamiento y orientación de los profesores.

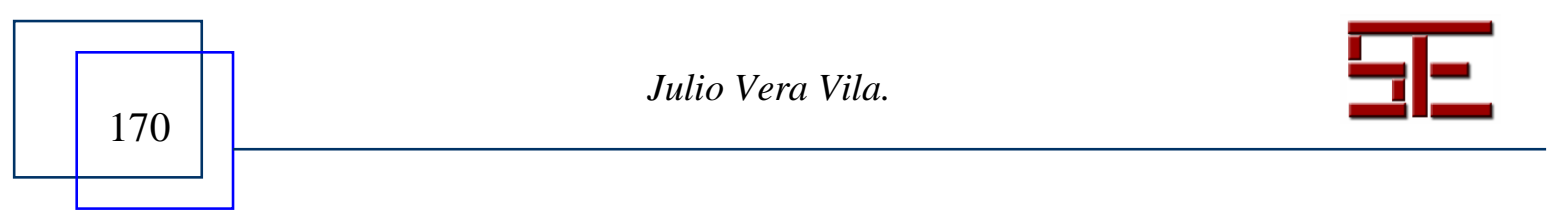




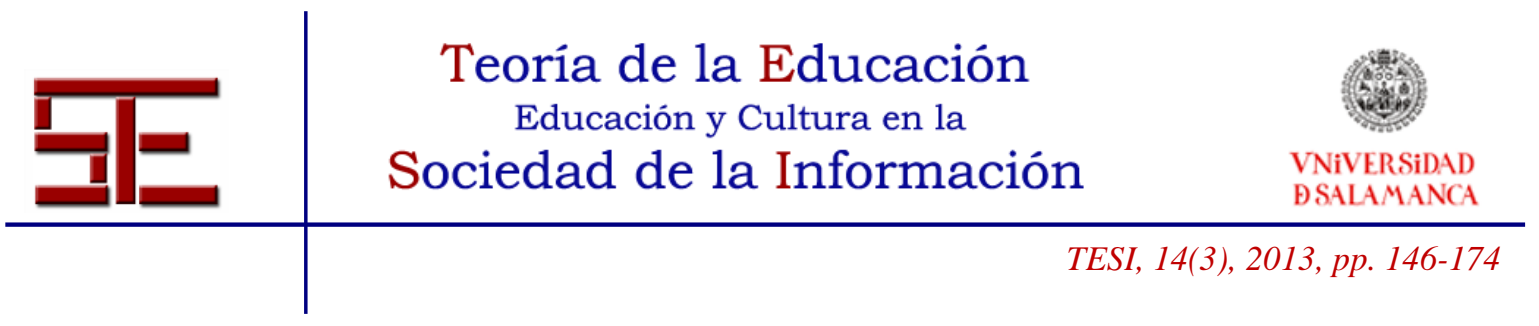

g) Para finalizar, aunque sea provisionalmente, todo aprendizaje ha de tener un sentido humanizador que trascienda su dimensión inmediata y que apunte a consideraciones éticas, convivenciales, de sostenibilidad comunitaria y medioambiental. Desde los primeros lenguajes a las últimas tecnologías, cada pequeño aprendizaje ha tenido consecuencias para la historia de la humanidad, sin que sea posible calibrar su trascendencia en ese instante en el que se produce, ni para el propio sujeto ni para el grupo. Esto no es nada trascendente, significa tan solo que cada vez que hacemos algo bien, evitamos que muchos otros tengan que ocuparse de nosotros en lugar de hacerlo por los que de verdad no tuvieron nuestras oportunidades.

Seguramente no hay nada que no pueda ser enseñado usando las TAC, como seguramente no hay nada que pueda ser aprendido sin ser competentes plurilingües, sin estar bien alfabetizados en las herramientas y en el sentido finalista de la vida. Darle un sentido a la vida propia ayuda a concentrar las energías en procesos y productos que hagan la vida más digna, más justa y también ¿por qué no? más bella. Creo que la teoría general de sistemas, teoría del caos (complejidad) y los planteamientos que defiende el profesor Colom nos ofrecen un marco teórico desde el que es más fácil entender el significado educativo de los cambios en las tecnologías de la información y la comunicación; y a la vez comprender cómo estos posibilitan la emergencia de nuevos entornos de aprendizaje, con nuevos lenguajes, nuevos modos de relación y de comunicación que pueden favorecer y potenciar nuestro desarrollo cognitivo y humano en general.

\section{REFERENCIAS}

Arsuaga, J.L. (2002). El collar de Neandertal. En busca de los primeros pensadores. Barcelona: Mondadori.

Bennet, S. , Matton, K. \& Kevin, L. (2008). The "digital natives" debate: A critical review of the evidence. British Journal Of Educational Technology, 39(5), 775786.

Bernard, M. (1993). Hypertexte: la troisème dimension du language, TEXTE, 13/14, 5.

Berners-Lee, Tim (2000). Tejiendo la red. Madrid: Siglo XXI.

Borges, J. L. (1941). El jardín de los senderos que se bifurcan. En Borges, J. L. (1971). Ficciones (11-126). Madrid: Alianza Editorial.

Carr, N. (2011). ¿Qué está haciendo internet con nuestras mentes? Superficiales. Madrid: Taurus.

Castells, M. (2001). La galaxia internet. Barcelona: Plaza y Janés.

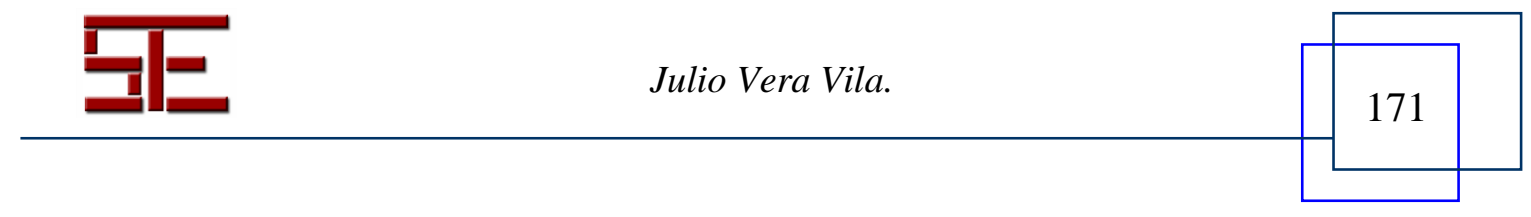




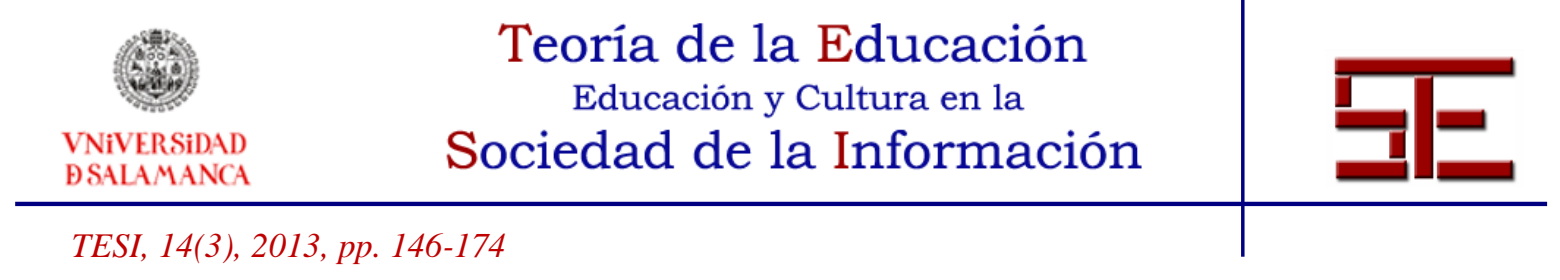

Colom, A. J. (2002). La (de)construcción del conocimiento pedagógico. Nuevas perspectivas en teoría de la educación. Barcelona: Paidós.

Cortázar, J. (1985). Rayuela. Barcelona: Planeta Agostini.

Doidge, N. (2008). El cerebro se cambia a sí mismo. Madrid: Aquilar.

Enzensberger, H. M. (1974). Elementos para una teoría de los medios de comunicación. Barcelona: Anagrama.

García Aretio, L. (Ed.) (2012). Sociedad del conocimiento y educación. Madrid: Uned.

García Carrasco, J. (2007). Leer en la cara y en el mundo. Barcelona: Herder.

García Carrasco, J. y García del Dujo, A. (2001). Teoría de la educación II. Procesos primarios de formación del pensamiento y la acción. Salamanca: Universidad de Salamanca.

García Carrasco, J. y otros (2012). Nuevos modos de aprendizaje en el contexto de la sociedad del conocimiento. En García Aretio, L. (Ed.), Sociedad del conocimiento y educación. Madrid: Uned, 305-339.

Gärdenfors, P. (2006). Cómo el homo se convirtió en sapiens. Madrid: Espasa Calpe.

Gardner, H. (1993). Estructuras de la mente. La teoría de las inteligencias múltiples. México: Fondo de Cultura Económica.

Havelock, E. (1976). Origins of Western Literacy. Ontario: Ontario Institute for studies in education.

Kerckhove, D. de (1999a). Inteligencias en conexión. Hacia una sociedad de la web. Barcelona: Gedisa.

Kerckhove, D. de (1999b). La piel de la cultura. Investigando la nueva realidad electrónica. Barcelona: Gedisa.

Lèvy, P. (2004). Inteligencia colectiva. Por una antropología del ciberespacio. Libro electrónico extraído el 10 de junio de 2013, de http://inteligenciacolectiva.bvsalud.org.

Martínez, I. y Arsuaga, J.L. (2002). Amalur. Del átomo a la mente. Madrid: Ediciones Temas de Hoy.

McLuhan, M. (2009). Comprender los medios de comunicación: las extensiones del ser humano. Barcelona: Paidós.

Morin, E. (1994). Introducción al pensamiento complejo. Barcelona: Gedisa.

Morin, E. (2001a). La mente bien ordenada. Barcelona: Seix Barral.

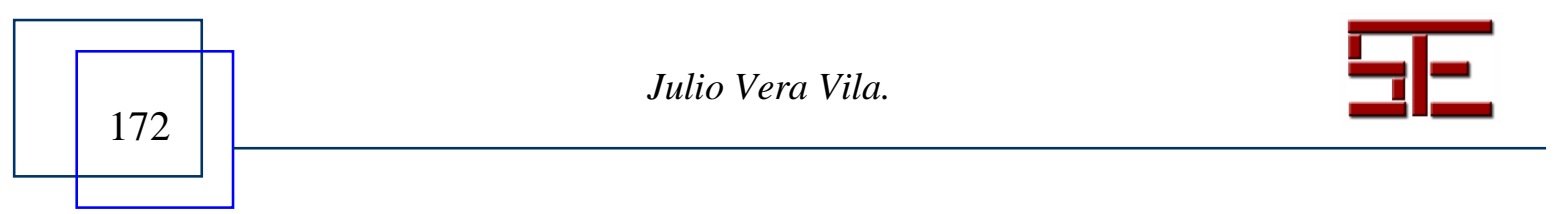




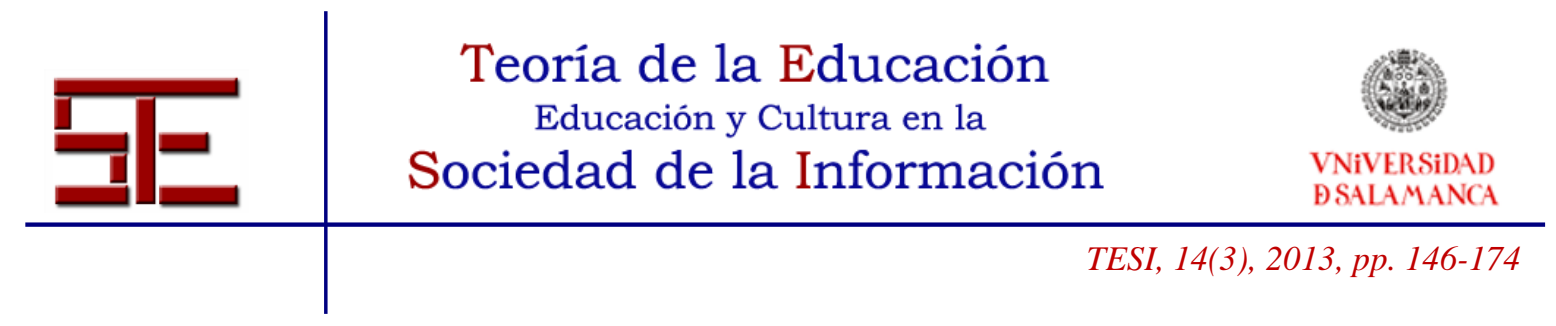

Morin, E. (2001b). Los siete saberes necesarios para la educación del futuro. Barcelona: Paidós.

Morin, E., Roger, E. y Motta, R.D. (2002). Educar en la era planetaria. El pensamiento complejo como método de aprendizaje en el error y la incertidumbre humana. Valladolid: Unesco/Universidad de Valladolid.

Olson, D. (1977). From utterances to text: The bias of languages in speech and writing. Harvard educational review, 47 (3), 257-281.

Ong, W. (1993). Oralidad y escritura. Buenos Aires: Fondo de Cultura Económica.

Pennac, D. (2008). Mal de escuela. Barcelona: Mondadori.

Plowman, L. y McPake, J. (2013). Seven Myths about young children and technology. Childhood Education, 89 (1), 27-33.

Prensky, M. (2001a) Digital natives, digital immigrants. On the horizon, MBC University Press, vol 9 (5).

Prensky, M. (2001b) Digital natives, digital immigrants, part II: Do they really think differently? On the horizon, MBC University Press, vol 9 (6).

Prensky, M. (2011). Homo sapiens digital: de los inmigrantes y nativos digitales a la sabiduría digital, en APARICI, R. (Coord.). Conectados en el ciberespacio (pp.93-106). Madrid: UNED.

Rodríguez Diéguez, J.L. (1995). El hipertexto. En Rodríguez Diéguez, J.L. y Sáenz Barrio, O. (Dir.). Tecnología educativa. Nuevas tecnologías aplicadas a la educación. (pp. 301-315). Alcoy: Marfil.

Siemens, G. (2011). Conectivismo: una teoría de aprendizaje para la era digital, en Aparici, R. (Coord.). Conectados en el ciberespacio (pp. 77-90). Madrid, UNED.

Vera, J. (1997). Cambio social y evaluación pedagógica de las tecnologías. Revista Española de Pedagogía, 207, 363-376.

Vera, J. (2008). Varias razones para leer bien y una buena razón para no leer nunca nada. En Asensio, J.M., et al. Lectura y Educación (pp.217-228). Barcelona, Universitat Autónoma de Barcelona.

Vera, J. (2010). La teoría de las inteligencias múltiples de Howard Gardner. En Sanchidrián y Berrio (Coord.), Historia y prospectiva actual de la educación infantil (307-327). Barcelona: Graó.

Viñao, A. (1989). Historia de la alfabetización versus historia del pensamiento, o sea, de la mente humana. En Delgado, B. y Rodríguez, M ${ }^{\mathrm{a}}$ L. (Coord.). Homenaje al profesor Alexandre Sanvisens (pp. 375-387). Barcelona: Universidad de Barcelona.

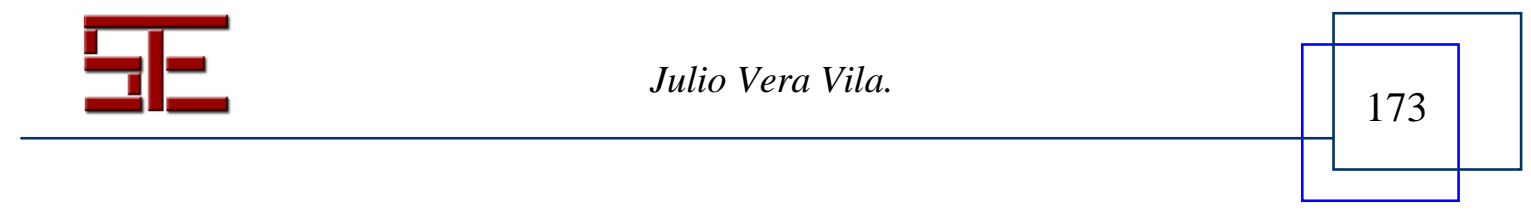




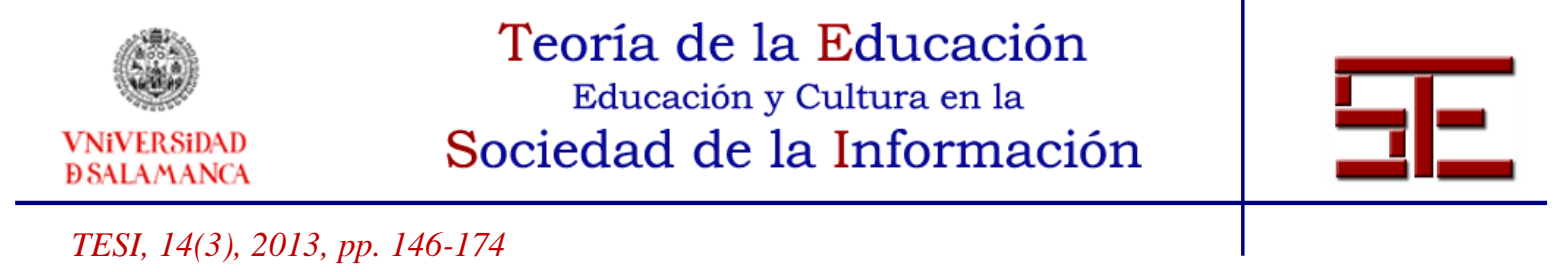

Viñao, A. (1999). Leer y escribir. Historia de dos prácticas culturales. México: Fundación ducación, voces y vuelos.

Vygotsky, L. (1962). Pensamiento y lenguaje. Buenos Aires: Lautaro.

Wolf, M. (2008): Cómo aprendemos a leer. Historia y ciencia del cerebro y la lectura. Barcelona: EdicionesB.

Para citar el presente artículo puede utilizar la siguiente referencia:

Vera Vila, J. (2013). Primeros lenguajes y últimas tecnologías para la educación. Revista Teoría de la Educación: Educación y Cultura en la Sociedad de la Información. 14(3), 146-174 [Fecha de consulta: dd/mm/aaaa].

http://campus.usal.es/ revistas_trabajo/index.php/revistatesi/article/view/11355/11772

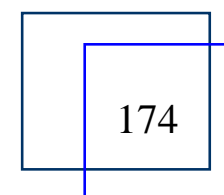

Julio Vera Vila. 